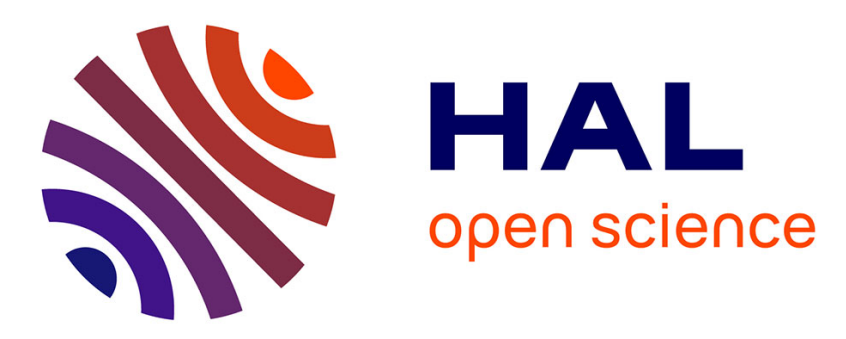

\title{
New Landscape of Electron-Pair Bonding: Covalent, Ionic, and Charge-Shift Bonds
}

\author{
Sason Shaik, David Danovich, Benoît Braïda, Wei Wu, Philippe C. Hiberty
}

\section{To cite this version:}

Sason Shaik, David Danovich, Benoît Braïda, Wei Wu, Philippe C. Hiberty. New Landscape of Electron-Pair Bonding: Covalent, Ionic, and Charge-Shift Bonds. Mingos, D. Michael P. The Chemical Bond II, 170, Springer International Publishing, pp.169-211, 2015, 978-3-319-33520-9 978-3-319-335223. hal-01627700

\section{HAL Id: hal-01627700 https://hal.science/hal-01627700}

Submitted on 10 Nov 2017

HAL is a multi-disciplinary open access archive for the deposit and dissemination of scientific research documents, whether they are published or not. The documents may come from teaching and research institutions in France or abroad, or from public or private research centers.
L'archive ouverte pluridisciplinaire HAL, est destinée au dépôt et à la diffusion de documents scientifiques de niveau recherche, publiés ou non, émanant des établissements d'enseignement et de recherche français ou étrangers, des laboratoires publics ou privés. 


\title{
New Landscape of Electron-Pair Bonding: Covalent, Ionic, and Charge-Shift Bonds
}

\author{
Sason Shaik, David Danovich, Benoit Braida, Wei Wu, \\ and Philippe C. Hiberty
}

\begin{abstract}
We discuss here the modern valence bond (VB) description of the electron-pair bond vis-à-vis the Lewis-Pauling model and show that along the two classical families of covalent and ionic bonds, there exists a family of charge-shift bonds (CSBS) in which the "resonance fluctuation" of the electronpair density plays a dominant role. A bridge is created between the VB description of bonding and three other approaches to the problem: the electron localization function (ELF), atoms-in-molecules (AIM), and molecular orbital (MO)-based theories. In VB theory, CSB manifests by repulsive or weakly bonded covalent state and large covalent-ionic resonance energy, $R E_{\mathrm{CS}}$. In ELF, it shows up by a depleted basin population with fluctuations and in AIM by a positive Laplacian. CSB is derivable also from MO-based theory. As such, CSB is shown to be $a$ fundamental mechanism that satisfies the equilibrium condition of bonding, namely, the virial ratio of the kinetic and potential energy contributions to the bond energy. The chapter defines the atomic propensity for CSB and outlines its territory: Atoms
\end{abstract}

\footnotetext{
S. Shaik $(\bowtie)$ and D. Danovich

Institute of Chemistry and the Lise-Meitner Minerva Center for Computational Quantum Chemistry, The Hebrew University, Jerusalem 9190401, Israel

e-mail: sason@yfaat.ch.huji.ac.il; david.danovich@mail.huji.ac.il

B. Braida

Sorbonne Universités, UPMC Univ. Paris 06, UMR 7616, LCT, 75005 Paris, France CNRS, UMR 7616, LCT, 75005 Paris, France

W. Wu

The State Key Laboratory of Physical Chemistry of Solid Surfaces, Fujian Provincial Key Laboratory of Theoretical and Computational Chemistry, and College of Chemistry and Chemical Engineering, Xiamen University, Xiamen, Fujian 361005, China

P.C. Hiberty $(\varangle)$

Laboratoire de Chimie Physique, UMR CNRS 8000, Groupe de Chimie Théorique,

Université de Paris-Sud, 91405 Orsay Cédex, France

e-mail: philippe.hiberty@u-psud.fr
} 
(fragments) that are prone to CSB are compact electronegative and/or lone-pair-rich species. As such, the territory of CSB transcends considerations of static charge distribution, and it involves (a) homopolar bonds of heteroatoms with zero static ionicity, (b) heteropolar $\sigma$ - and $\pi$-bonds of the electronegative and/or electron-pairrich elements among themselves and to other atoms (e.g., the higher metalloids, $\mathrm{Si}$, $\mathrm{Ge}, \mathrm{Sn}$, etc.), and (c) electron-rich hypercoordinate molecules. Several experimental manifestations of charge-shift bonding are discussed.

Keywords AIM - Bonding · Charge-shift bonding · Covalent bonding · Electron pairing · Electronegativity · ELF · Ionic bonding · Lewis structures · Resonance energy $\cdot$ Valence bond

\section{Contents}

1 Introduction

2 The Development of the Notion of Electron-Pair Bonding

3 The Valence Bond Description of the Two-Electron Bond

3.1 The Pauling Covalent-Ionic Superposition Scheme of the Two-Electron Bond

3.2 Limitations of the Pauling Scheme

4 A Modern VB Perspective of the Two-Electron Bond

5 Characterization of CSB by Other Theoretical Methods

5.1 VB Characterization of Bond Types

5.2 ELF and AIM Characterization of Bond Types

6 Common Trends of Bond Types Revealed by VB, AIM, and ELF

6.1 Common Conclusions in VB and AIM Analyses of Bonds

6.2 Common Conclusions in VB and ELF Analyses of Bonds

6.3 Common Conclusions in VB, ELF, and AIM Analyses of Bonds

6.4 The Three Bonding Families

7 How Does MO Theory Reveal CSB?

8 Physical Origins of CSB

8.1 CSB and Atomic Size

8.2 The Pauli Repulsion Pressure as a Driving Force for CSB

9 Trends in Electron-Pair Bonds

10 Additional Factors of CSB

11 Transforming Covalent Bonds to CSBs by Substitution

12 Experimental Manifestations of CS Bonding

12.1 Evidence for CSB from Electron Density Measurements

12.2 Atom Transfer Reactivity as Means of Experimental Quantification of ChargeShift Resonance Energies

12.3 Mechanistic Impacts of CSB in the Ionic Chemistry of Silicon in Condensed Phases

13 CSB and Electron-Rich Hypervalent Molecules

13.1 Hypervalency of Noble Gas and Isoelectronic Groups

13.2 Pentacoordinated Silicon Compounds and Low-Barrier Hydrogen Bonds

14 Scope and Territory of CS Bonding and Concluding Remarks

References 


\section{Introduction}

The conceptual element from which an entire chemical universe can be constructed is the chemical bond [1]. As such, the bond is the "quantum building block" of the grand scheme of "LEGO" by which practicing chemists devise and control the formation of new molecules of ever-increasing complexity and beauty. In this respect, the chemical community owes a great debt to Lewis who was the first to define the chemical bond in terms of electronic structure [1], well before the quantum mechanical revolution transpired in physics and provided a rigorous basis for the Lewis concept in terms of what we call today valence bond (VB) theory [2]. This Lewis Centennial Volume is hence a tribute to one of the greatest chemists whose ideas are still the foundations of our way of thinking 100 years after their conception. This contribution recounts the new VB outlook of bonding with a focus on the two-electron bond as the most ubiquitous bonding form in nature.

As we shall show, the articulation of the bond paradigm requires that alongside the traditional covalent (polar-covalent) and ionic bonds, there should exist a third and a distinct class of bonding, the so-called charge-shift bonding (CSB) [3-15], which has unique experimental signatures. We shall describe these three classes and form bridges to other theories by demonstrating that CSB can be articulated also from theories based on electron density consideration, specifically the electron localization function (ELF) [16] and atoms-in-molecules (AIM) [17] theories, as well as from MO theory [14]. Other bond types, odd-electron and hypervalent bonds, which also belong to the CSB family, will be mentioned in passing.

The paper introduces initially Pauling's application of VB theory to derive the classical bond families outlined in the original Lewis paper [1]. The second part questions the underlying assumptions of Pauling's scheme and shows that waiving the key assumption naturally leads to the emergence of the CSB family along with the two traditional ones. Then modern VB theory [18] is used to support the existence of three bond families, covalent, ionic, and CSB. Details on modern VB theory can be found in review sources $[18,19]$. In the third part of the paper, we show how the new family of CSB emerges also from ELF and AIM theories, as well as from MO theory. Subsequently, we discuss the physical origins of CSB and describe experimental manifestations of this new bond family. Finally, we try to trace the potential territory of CSB and where novel experimental articulations of the CSB theory may be productive.

\section{The Development of the Notion of Electron-Pair Bonding}

The concept of the electron-pair bond was formulated in a stroke of genius by Gilbert Newton Lewis in his famous 1916 JACS article, "The Atom and the Molecule" [20], in which he introduced the concept of the electron-pair bond as an intrinsic property that stretches between the covalent and ionic situations. This 
work has eventually had its greatest impact in chemistry through the work of Irving Langmuir [21], who ably articulated the Lewis concept, coining new and catchy terms [22]. However, the mechanism whereby the electron pair could constitute a bond remained mysterious until 1927, when Walter Heitler and Fritz London published their seminal paper [23], which calculates the bonding energy in $\mathrm{H}_{2}$. Using a modern terminology, the bond energy in $\mathrm{H}_{2}$ was shown to arise from the resonance interaction between the two spin arrangement patterns, $\mathrm{H}^{\uparrow} \mathrm{H}^{\downarrow}$ and $\mathrm{H}^{\downarrow} \mathrm{H}^{\uparrow}$, required to generate a singlet electron pair $\left[\Phi_{\text {cov }}\right.$ in Eq. (1)]. In the winter of 1928 , London [24] drew the basic principles of the nonionic bond, and his theory was in essence a quantum mechanical articulation of Lewis' covalent bond:

$$
\Phi_{\text {cov }}(\mathrm{H} \bullet-\bullet \mathrm{H})=\mathrm{H}^{\uparrow \downarrow} \mathrm{H} \leftrightarrow \mathrm{H}^{\downarrow \uparrow} \mathrm{H} .
$$

The Heitler-London papers mark the birth of VB theory [2], which was developed by Pauling as a quantum mechanical version of the Lewis model. This quantum mechanical articulation of Lewis' shared-pair model has culminated in a generalizing intellectual construct [25], which described the electron-pair bond A-X as a superposition of covalent $\left(\Phi_{\text {cov }}\right)$ and ionic forms, $\Phi_{A}{ } X^{-}$and $\Phi_{A}-X^{+}$[Eq. (2a) and (2b)].

$$
\begin{gathered}
\Phi(\mathrm{A}-\mathrm{X})=\mathrm{A} \bullet-\mathrm{X} \leftrightarrow \mathrm{A}^{+}: \mathrm{X}^{-} \leftrightarrow \mathrm{A}:{ }^{-} \mathrm{X}^{+} \\
=\Phi_{\operatorname{cov}(\mathrm{A} \bullet-\bullet \mathrm{X})} \leftrightarrow \Phi_{\mathrm{A}^{+} \mathrm{X}^{-}} \leftrightarrow \Phi_{\mathrm{A}^{-} \mathrm{X}^{+}}
\end{gathered}
$$

This picture enabled a unified description of bonding in any molecule, in terms of VB theory. Slater and van Vleck showed $[26,27]$ that an MO treatment followed by complete configuration interaction is equivalent to the VB-based covalent-ionic scheme of Pauling. In retrospect, reading Lewis' paper shows that he anticipated the ideas that underlie the physical organic chemistry school [22, 28, 29] of Ingold and the resonance concept $[28,30]$ expounded by Pauling. Thus, the birth of VB theory in chemistry was an ingenious quantum chemical dressing of Lewis' seminal idea by Pauling and can be referred to as the Pauling-Lewis VB theory.

\section{The Valence Bond Description of the Two-Electron Bond}

\subsection{The Pauling Covalent-Ionic Superposition Scheme of the Two-Electron Bond}

Figure 1 describes the Pauling-Lewis perspective of electron-pair bonding in terms of VB mixing diagrams [9]. Three structures, one covalent, $\Phi_{\operatorname{cov}(\mathrm{A} \bullet \bullet \cdot \mathrm{X})}$, and two ionic ones, $\Phi_{\mathrm{A}^{+} \mathrm{X}^{-}}$and $\Phi_{\mathrm{A}^{-} \mathrm{X}^{+}}$, are required to describe an electron pair bond $\mathrm{A}-\mathrm{X}$, which may either be homo- or heteronuclear. 
(a)

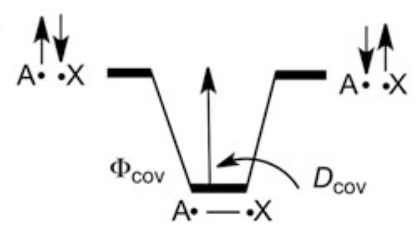

(b)

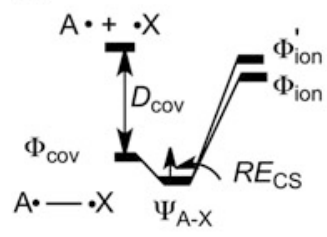

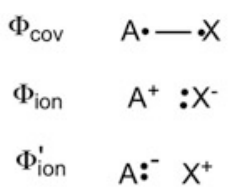

(c)

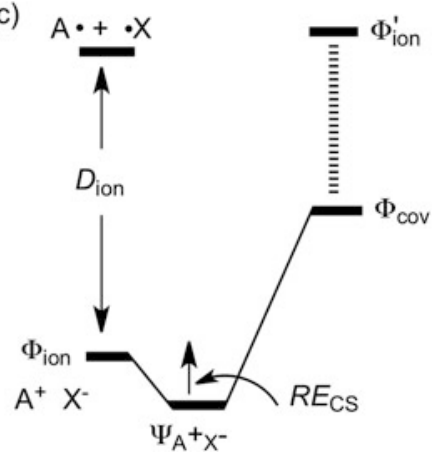

Fig. 1 Piecing up the A-X bond by means of VB mixing diagrams. (a) The covalent structure is stabilized by $D_{\text {cov }}$ due to resonance between the two spin arrangement patterns required to create a singlet pair. (b) The covalent-ionic mixing for a polar-covalent A-X bond. (c) The covalent-ionic mixing for an ionic $\mathrm{A}^{+}: \mathrm{X}^{-}$bond. $D_{\text {ion }}$ is the difference of the electrostatic stabilization of the ionic structure less the energy needed to create the ions from the atoms. In both (b) and (c), $R E_{\mathrm{CS}}$ is the covalent-ionic resonance energy, so-called in this manuscript as the charge-shift resonance energy

The covalent structure $\Phi_{\text {cov }}$ (Fig. 1a) is stabilized by spin pairing due to the resonance of the $\mathrm{A}^{\uparrow} \mathrm{X}^{\downarrow}$ and $\mathrm{A}^{\downarrow} \mathrm{X}^{\uparrow}$ spin arrangement forms. This contributes to the covalent bond energy due to spin pairing, denoted as $D_{\text {cov }}$. For a dominantly covalent bond, where $\Phi_{\text {cov }}$ is the lowest VB structure (Fig. 1b), this stabilization energy $D_{\text {cov }}$ is the covalent contribution to the total bonding energy. On the other hand, ionic structures are stabilized by electrostatic interactions, relative to the separated atoms by an amount $D_{\text {ion }}$. When an ionic form, e.g., $\Phi_{\mathrm{A}}{ }^{+}{ }^{-}$, is the lowest among the VB structures (Fig. 1c), the bond is ionic and the electrostatic stabilization energy is the dominant contribution to the bond energy. The covalent-ionic mixing results in a resonance energy contribution that augments, in principle, the bonding of either covalent or ionic bonds. The original literature refers to this quantity as the "charge-shift resonance energy," $R E_{\mathrm{CS}}$ [3-15], because the pair density inherent in the VB wave function shows that covalent-ionic mixing is associated with fluctuation of the electron pair from the average electron population. As we shall see later, the $R E_{\mathrm{CS}}$ quantity figures prominently in the chargeshift bonding (CSB) motif. 
Scheme 1 The traditional covalent and ionic bond families based on Pauling's covalent-ionic superposition scheme. Reproduced from [9] with permission of Wiley-VCH

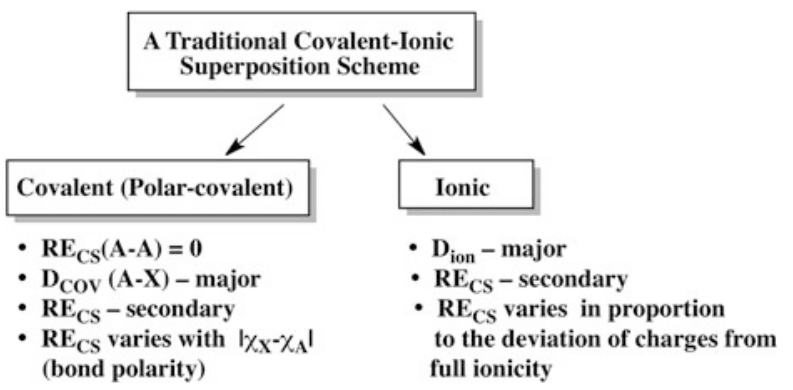

To use the scheme to calculate bond energies, Pauling assumed that for homonuclear bonds $R E_{\mathrm{CS}}=0^{1}$. On the other hand, $R E_{\mathrm{CS}}$ was assumed to be nonzero for heteronuclear bonds $\mathrm{A}-\mathrm{X}$. In accord, the dissociation energy $D_{\mathrm{AX}}$ of an $\mathrm{A}-\mathrm{X}$ bond was considered as being made of a purely covalent contribution, $D_{\operatorname{cov}(\mathrm{A} \bullet-\mathrm{X})}$, augmented by the resonance energy due to covalent-ionic mixing. The covalent contribution was estimated as the geometric average of the bond energies of the two corresponding homonuclear bonds, $\mathrm{A}-\mathrm{A}$ and $\mathrm{X}-\mathrm{X}$, as in Eq. (3):

$$
D_{\operatorname{cov}(\mathrm{A} \bullet-\bullet \mathrm{X})}=\left(D_{\mathrm{AA}} \bullet D_{\mathrm{XX}}\right)^{1 / 2} \text {. }
$$

Using Eq. (3), the remaining contribution to the actual bond energy, $D_{\mathrm{Ax}}$, was considered to be the resonance energy due to covalent-ionic mixing, and this value was used to gauge the electronegativity scale, as shown in Eq. (4):

$$
D_{\mathrm{AX}}-D_{\operatorname{cov}(\mathrm{A} \bullet-\bullet \mathrm{X})}\left(\mathrm{kcal} \mathrm{mol}^{-1}\right)=23\left(\chi_{\mathrm{x}}-\chi_{\mathrm{A}}\right)^{2},
$$

where $\chi$ is the electronegativity. Furthermore, once the electronegativity is known, the "bond polarity" $(\delta)$ can be quantified as in Eq. (5), thereby providing the extent of ionic $\mathrm{A}^{+} \mathrm{X}^{-}$character in the bond:

$$
\delta=1-\exp \left[-0.25\left(\chi_{\mathrm{x}}-\chi_{\mathrm{A}}\right)^{2}\right]
$$

As such, in practice, the Pauling covalent-ionic superposition scheme has traditionally become associated with two bond families, based on a criterion of static charge distribution; these are the covalent (polar-covalent) bond and ionic bond families in Scheme 1. In the first family, the major contribution to bonding comes from spin pairing. Importantly, in homopolar bonds, the $R E_{\mathrm{CS}}$ contribution was assumed - in Pauling's original scheme ${ }^{1}$ and in subsequent treatments based on

\footnotetext{
${ }^{1}$ The use of $R E_{\mathrm{CS}}(\mathrm{A}-\mathrm{A}) \approx 0$ appears as a working assumption, e.g., on pages 73-100 (see also footnote 13 on page 73), in [25] where it is estimated that the ionic structures in, e.g., $\mathrm{Cl}_{2}$ will contribute less than $2 \%$ to the total bond energy. A stricter assumption is used in Sanderson's treatment ([31] below), which neglects the resonance energy altogether.
} 
it - to be very small and was set to zero. In heteropolar bonds, the primary contribution to bonding is normally considered to be the $D_{\text {cov }}$ quantity ${ }^{1}$, while the charge-shift resonance energy is of secondary importance, except for very polar bonds involving the very electronegative atoms. Furthermore, as shown by Eq. (4), the magnitude of $R E_{\mathrm{CS}}$ is considered to vary in proportion to the electronegativity difference of the fragments, $\mathrm{A}$ and $\mathrm{X}$, much like the charge distribution, i.e., the "bond polarity" in Eq. (5).

In the second family, the major bonding contribution comes from the electrostatic energy in the dominant ionic structure, whereas $R E_{\mathrm{CS}}$ is a minor factor; its magnitude is supposed to vary in proportion to the deviation of the charge distribution from full ionicity.

As such, in the traditional classification of both bonding types, it is assumed that one can deduce the magnitude of the covalent-ionic resonance energy by simply inspecting the static charge distribution of the molecule.

Using MO theory, it is possible to transform the delocalized canonical MOs to a set of localized MOs (LMOs) that describe two-center bonds (for pioneering localization methods, see [32-37]). The LMOs retrieve the covalent-ionic superposition scheme as follows: The electron-pair bond is the LMO itself, while the covalent-ionic superposition can be quantified from the charge polarization of the LMO; namely, the relative size of the coefficients of the hybrids of the contributing fragments to the LMO determines the bond polarity. Accordingly, MO theory leads in principle to the same electron-pair bonding picture as the classical covalent-ionic paradigm of Pauling. In fact, both VB and MO descriptions are simply articulations of the original Lewis formulation of electron-pair bonding.

\subsection{Limitations of the Pauling Scheme}

Thus, our bonding paradigm is now 100 years old [20], and yet even a cursory search in the literature suggests that this is perhaps not the whole story. Just consider the bonds of silicon to electronegative atoms. By criterion of the static charge distribution, these bonds are virtually as ionic as, e.g., $\mathrm{LiF}$ or $\mathrm{NaCl}$ (e.g., $\mathrm{H}_{3} \mathrm{Si}^{+0.85} \mathrm{~F}^{-0.85}$ vs. $\mathrm{Li}^{+0.94} \mathrm{~F}^{-0.94}, \mathrm{Na}^{+0.91} \mathrm{Cl}^{-0.91}$, etc. $)^{2}$ [38]. But, while $\mathrm{Li}^{+} \mathrm{F}^{-}$and $\mathrm{Na}^{+} \mathrm{Cl}^{-}$behave as genuine ionic bonds, the $\mathrm{Si}^{+} \mathrm{X}^{-}$bonds behave chemically as covalent bonds [39-45]. The bonds look so similar, yet they are so very different in their chemical behavior. Indeed, all $\mathrm{Si}-\mathrm{X}$ bonds are more ionic than the corresponding $\mathrm{C}-\mathrm{X}$ bonds [40] according to static charge distribution, and nevertheless, these are the $\mathrm{C}-\mathrm{X}$ bonds that exhibit ionic chemistry in condensed phases, whereas the ionic Si-X chemistry is extremely rare [40-46] with a handful of exceptions [47, 48]. For example, trityl perchlorate, $\mathrm{Ph}_{3} \mathrm{C}^{+} \mathrm{ClO}_{4}{ }^{-}$, is an ionic

\footnotetext{
${ }^{2}$ Silvi B, AIM analysis, of $\mathrm{SiH}_{3}-\mathrm{F}$ and $\mathrm{Li}-\mathrm{F}$ using B3LYP/6-31+G* and B3LYP/6-31G* levels cited in [9] above
} 
solid like $\mathrm{NaCl}$ [46], while the silicon analog is a covalent solid with a short $\mathrm{Si}-\mathrm{O}$ bond [42]. It is apparent therefore that the static charge distribution is not a reliable indicator of the nature of bonding. There must be an additional property of the bond that is missing in the traditional covalent-ionic superposition scheme.

This property is $R E_{\mathrm{CS}}$. In fact, the Pauling construct, in Fig. 1, Eqs. (3)-(5), and Scheme 1, considers the covalent and ionic structures to be generators of bonding families but overlooks their resonance energies as a potential generator of a third family. The major problem is associated with the assumption that for homonuclear bond $R E_{\mathrm{CS}}=0$. This assumption undermines the role of $R E_{\mathrm{CS}}$ and overestimates the magnitude of $D_{\text {cov }}$. As shown later, this assumption is factually incorrect, and its implementation leads to a loss of an entire bond family, the so-called charge-shift bonds $(C S B s)$.

\section{A Modern VB Perspective of the Two-Electron Bond}

These and many similar puzzles have prompted two of us (SS and PCH) in 1990 to reexamine the classical covalent-ionic paradigm using the tools of ab initio VB theory [3-15]. The interested reader in modern VB theory can consult a recent monograph and a review $[18,19]$. Our first intriguing findings [3, 4] concerned the F-F bond, which has been intensely debated and which requires quite a high level of configuration interaction to yield a quantitatively correct bond energy ${ }^{3}$ (see also [49-51]). By any known measure, the F-F bond would be defined as a "covalent bond." Firstly, it is a homonuclear bond, where ionicity should not matter. Secondly, the weight of its covalent structure is as large as that for the $\mathrm{H}-\mathrm{H}$ bond $[3,4$, 9]. Is the $\mathrm{F}-\mathrm{F}$ bond really covalent as the $\mathrm{H}-\mathrm{H}$ bond? The answer according to Fig. 2 is "no."

Figure 2 displays the dissociation energy curves of a few bonds showing the dominant VB structure of the bond alongside the "exact" ground state, which is a resonating combination of the covalent and ionic components, calculated by means of modern VB theory. Inspection of Fig. 2a, b makes it apparent that the bonding natures of the $\mathrm{H}-\mathrm{H}$ and $\mathrm{F}-\mathrm{F}$ bonds are very different. While in $\mathrm{H}_{2}$ the covalent VB structure displays by itself a potential well, which is already a good approximation of the exact curve (Fig. 2a), the covalent component of $\mathrm{F}_{2}$ is on the contrary purely repulsive (Fig. 2b). Thus, covalent spin pairing does not contribute anything to $\mathrm{F}-\mathrm{F}$ bonding. The bonding is in fact sustained by the very large charge-shift resonance energy due to the mixing of the higher lying ionic structures (not shown in the Figure) into the repulsive covalent structure. Thus, although F-F may be formally a covalent bond according to its zero static charge distribution, this definition cannot

\footnotetext{
${ }^{3}$ As seen from Table 10.2 of [2], CASSCF/6-31G* or GVB/6-31G* lead to BDE values of $\sim 16.0 \mathrm{kcal} \mathrm{mol}^{-1}$, compared with the experimental value of $38.3 \mathrm{kcal} \mathrm{mol}^{-1}$. Using $\mathrm{MRCI} / \mathrm{cc}-$ $\mathrm{pVTZ}$, the value is $35.9 \mathrm{kcal} \mathrm{mol}^{-1}$.
} 
New Landscape of Electron-Pair Bonding: Covalent, Ionic, and Charge-Shift Bonds
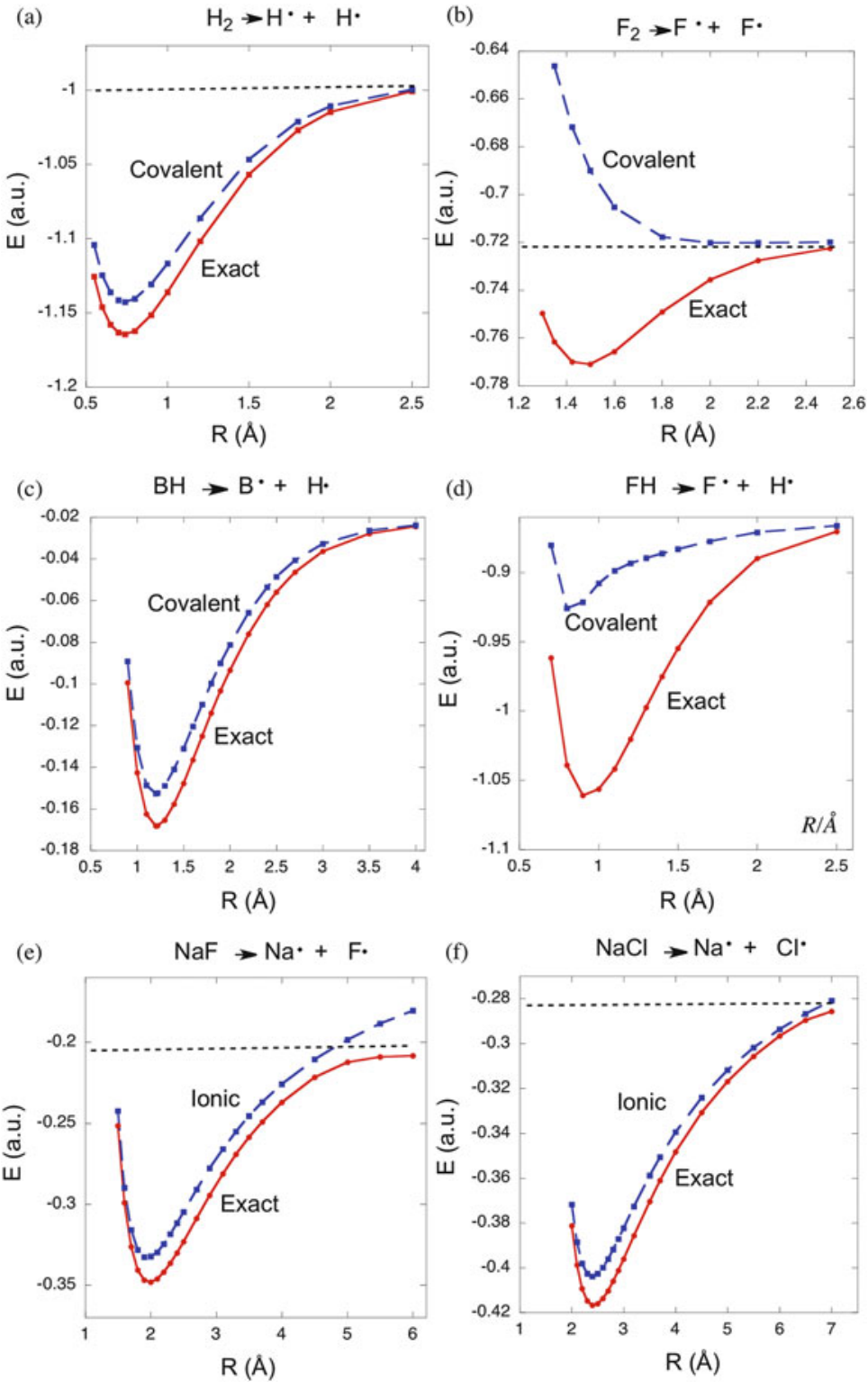

Fig. 2 Dissociation energy curves for (a) $\mathrm{H}_{2}$, (b) $\mathrm{F}_{2}$, (c) $\mathrm{BH}$, (d) $\mathrm{FH}$, (e) $\mathrm{NaF}$, and (f) $\mathrm{NaCl}$. The blue lines with squares show the purely covalent VB structures. Red lines with squares show the optimized covalent + ionic "exact" ground state. Reproduced from [12] with permission of Nature Chemistry 
tag its true nature; the F-F bond is in fact a charge-shift bond (CSB), because the bonding exists as a result of the ionic-covalent fluctuation of the electron-pair density. This F-F case shows that the assumption underlying the classical Pauling scheme (Scheme 1) is incorrect; the covalent bonding by itself is not necessarily stabilizing even for homopolar bonds and even in case where the covalent structure clearly dominates the wave function, having the highest coefficient, as in F-F. Importantly, homopolar bonds can have very large charge-shift resonance energies. Moreover, the appearance of a repulsive covalent structure shows that these structures can be repulsive when the covalent spin-pairing energy is frustrated by Pauli repulsion (the same-spin interaction of the lone-pair electrons with the bonding electrons in the covalent structure). We shall elaborate this point later when we discuss the physical origins of CSB, and we shall see that once the assumption in Pauling scheme is removed, this enables to re-chart the mental map of the chemical bond.

However, CSB is not restricted to F-F, as can be seen by comparing Fig. 2d to c. It is clear that the $\mathrm{B}-\mathrm{H}$ bond is classically covalent, while the $\mathrm{F}-\mathrm{H}$ bond is not; its covalent structure is weakly bonded while the majority of the bonding energy in the exact $\mathrm{VB}$ wave function arises from the $R E_{\mathrm{CS}}$ due to the mixing of the ionic structures. Thus, here the Pauli repulsion weakens very much the covalent bonding, but not to the extent found in Fig. 2b for F-F.

Finally, Fig. 2e, f shows the $\mathrm{NaF}$ and $\mathrm{NaCl}$ bonds. It is clear that for both bonds, the dominant VB structure is ionic and it is very close to the exact covalent-ionic superposition curve, with a negligible $R E_{\mathrm{CS}}$ contribution. These two bonds are classically ionic.

As such, Fig. 2 reveals very nicely the two classical bond families, covalent and ionic, but alongside them, it reveals also the presence of a third bond type, wherein the bonding does not arise from any one of the covalent or ionic structures, but rather from the resonance interaction, $R E_{C S}$, between them. This is the charge-shift bonding (CSB) family. In recent years, a variety of $\sigma$ - and $\pi$-bonds, both homo- and heteronuclear, were shown to share this property, thereby forming a growing family of CSBs [3-15], which we are going to focus upon in the remaining text.

\section{Characterization of CSB by Other Theoretical Methods}

The eventual acceptance of the CSB concept in chemistry ultimately depends on three conditions: (a) that the concept is proven to be robust and derivable from whichever theory one uses, (b) that manifestations of CSB in experimental data are found, and (c) that the concept leads to some testable predictions. We shall start by finding alternative theoretical probes for bonding and especially for the signatures of CSB. 


\subsection{VB Characterization of Bond Types}

As discussed above, the emergence of three bonding families, covalent, ionic, and CS bonds, was originally derived from modern VB calculations [3, 4]. Thus, the VB wave function of an $\mathrm{A}-\mathrm{X}$ bond was computed as a combination of the covalent form, $\Phi_{\text {cov }}(\mathrm{A} \bullet-\bullet \mathrm{X})$, and the two ionic forms, $\Phi_{\mathrm{ion}}\left(\mathrm{A}^{+} \mathrm{X}^{-}\right)$and $\Phi_{\mathrm{ion}}^{\prime}\left(\mathrm{A}^{-} \mathrm{X}^{+}\right)$, shown in Fig. 1 and in Eq. (6):

$$
\Psi(\mathrm{VB})=\mathrm{c}_{1} \Phi_{\mathrm{cov}}+\mathrm{c}_{2} \Phi_{\text {ion }}+\mathrm{c}_{3} \Phi_{\text {ion }}^{\prime}
$$

Equation (6) is identical to the Pauling wave function (see above), but all the terms are now computed by means of ab initio VB theory [18, 19]. The principal VB structure is the one having the lowest energy and hence also the largest coefficient among the three structures in Eq. (6). Its contribution to the total bond dissociation energy $\left(D_{\mathrm{e}}\right)$ is referred to as either $D_{\text {cov }}$ or $D_{\text {ion }}$, wherein the subscript specifies the dominant $\mathrm{VB}$ structure. In all cases, the $R E_{\mathrm{CS}}$ is determined by reference to the bonding energy of the principal VB structure, as expressed by Eqs. (7a) and (7b):

$$
\begin{gathered}
D_{\mathrm{e}}(\text { polar }- \text { covalent })=D_{\mathrm{cov}}+R E_{\mathrm{CS}}, \\
D_{\mathrm{e}}(\text { ionic })=D_{\text {ion }}+R E_{\mathrm{CS}} .
\end{gathered}
$$

Note that Eq. (7a) covers both covalent and CSBs, depending on the magnitude of $R E_{\mathrm{CS}}$ vis-à-vis the total bond energy $D_{e}$. Similarly, Eq. (7b) covers both ionic and strongly polar CSBs, wherein the ionic structure dominates the wave function. These quantities characterize the bonding type as revealed from Fig. 2. Thus, in Fig. 2a, c, the principal VB structure for both $\mathrm{H}-\mathrm{H}$ and $\mathrm{B}-\mathrm{H}$ is $\Phi_{\text {cov }}$, while the $R E_{\mathrm{CS}}$ quantity is small and much less significant than the large $D_{\text {cov }}$. In accord, these bonds are classical covalent and polar-covalent types, respectively. By contrast, F$\mathrm{H}$ in Fig. 2d displays a weakly bound principal structure $\Phi_{\text {cov }}$, and the major contribution to the bond comes from $R E_{\mathrm{CS}} ; \mathrm{H}-\mathrm{F}$ is a CSB. An extreme CSB case is the F-F bond, in Fig. 2b, in which the principal structure $\Phi_{\text {cov }}$ is not even bonded, i.e., $D_{\text {cov }}$ is negative, while $R E_{\mathrm{CS}}$ is even larger than the total bonding energy. Finally, in $\mathrm{Na}-\mathrm{F}$ and $\mathrm{Na}-\mathrm{Cl}$ (Fig. 2e and f), the principal VB structure is now $\Phi_{\text {ion }}$, and the $R E_{\mathrm{CS}}$ quantity is a minor contributor, making both classical ionic bonds, where most of the bonding energy arises from the ionic structure.

\subsection{ELF and AIM Characterization of Bond Types}

An alternative way to characterize bonding uses electron density theories, like electron localization function (ELF) [16] and atoms in molecules (AIM) [17]. Will ELF and AIM show these three families? What will be the ELF and AIM signatures for CS bonds? 
Scheme 2 Ideal covalent and ionic bonds and their expected ELF properties. Reproduced from [9] with permission of Wiley-VCH

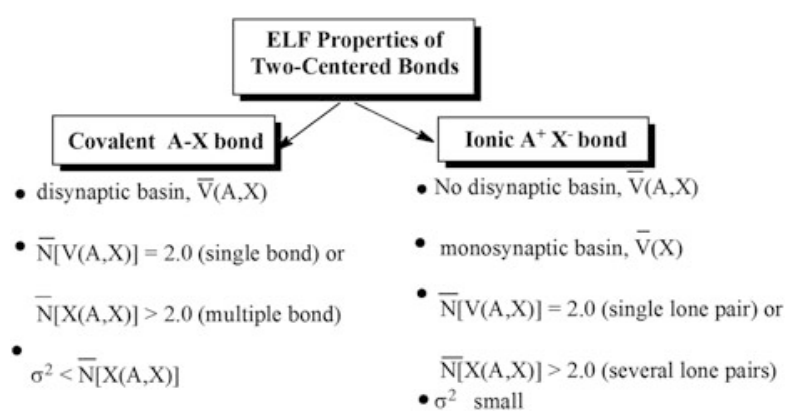

\subsubsection{ELF Characterization of Bond Types}

The ELF approach uses a local function related to the Pauli repulsion to probe the separation of the different electron pairs and from this analysis carries out a partition of the molecular space into basins that correspond to the volumes occupied by core inner shells, bonds, and lone pairs. As in the Lewis model, a valence basin may either belong to a single atomic shell or be shared by several ones. In the first case, the basin is called monosynaptic and corresponds to a lone-pair region, and in the second case, it is polysynaptic and specifically disynaptic for a two-center bond that is of interest in this chapter.

A given basin is typified by a statistical analysis of the density. Thus, it is possible to calculate the basin population, $\bar{N}$, and its variance, $\sigma^{2}$, by integrating the one-electron and the pair density over the volumes of the corresponding basins. In the statistical theory of the basin populations, the variances measure the electron fluctuation in a given basin, and the covariances $[9,52]$ are thought to gauge directly the covalent-ionic fluctuations in terms of weights of ionic structures. However, since the covariance values exhibit similar trends to those of the variance [9], we shall focus only on the latter quantities.

For a classical covalent bond, the basin is disynaptic, its population is close to 2.0, and the variance (and covariance) is significantly smaller than the population, while a classical ionic bond like $\mathrm{NaCl}$ has only core and monosynaptic basins $[9,16,53]$. Scheme 2 summarizes these features, which defines only two electronpair bond families, either covalent or ionic, in the original ELF formulations. Any bond with very different values, for the basin population and the corresponding fluctuation index, will not qualify as either covalent or ionic. However, as will be shown immediately, CSB possesses unique ELF characteristics, which foretell the repulsive (or slightly attractive) covalent density.

\subsubsection{AIM Characterization of Bond Types}

In AIM theory [17], a bond is generally characterized by a bond path, which defines a maximum density path connecting the bonded atoms. The point of the path at 
which the density is at minimum is called the bond critical point (BCP), and the values of the density, $\rho\left(\mathbf{r}_{\mathrm{c}}\right)$, and its Laplacian, $\nabla^{2} \rho\left(\mathbf{r}_{\mathrm{c}}\right)$, at this point are characteristics of the interaction type in the bonding region. According to AIM, a classical covalent bond is typified by a significant $\rho\left(\mathbf{r}_{\mathrm{c}}\right)$ value and a large negative $\nabla^{2} \rho\left(\mathbf{r}_{\mathrm{c}}\right)$. By contrast, closed-shell interactions, suffering from Pauli repulsions (also known as overlap repulsion or exchange repulsion), as in ionic bonds or the $\mathrm{He} / \mathrm{He}$ interaction, have characteristically a small critical density and a positive Laplacian. Note that the coexistence of a significant BCP density along with a positive Laplacian is not considered in the original AIM theory [17] and is viewed as an exception [54]. As will be seen below, this combination of features is in fact the signature of a homonuclear CS bond.

The Laplacian is especially telling quantity $[17,55]$, since it is connected to the kinetic and potential energy densities at BCP, $G\left(\mathbf{r}_{\mathrm{c}}\right)$ and $V\left(\mathbf{r}_{\mathrm{c}}\right)$, respectively, by the following local-virial theorem expression:

$$
\frac{\hbar^{2}}{4 m} \nabla^{2} \rho\left(\mathbf{r}_{\mathrm{c}}\right)=2 G\left(\mathbf{r}_{\mathrm{c}}\right)+V\left(\mathbf{r}_{\mathrm{c}}\right) .
$$

Thus, a negative Laplacian means that the bonding region is dominated by lowering of the potential energy, while a positive Laplacian means that the interaction in the bonding region is typified by excess kinetic energy and is hence repulsive. All the AIM parameters for bonds in a molecule can be either calculated or derived from experimental density determination and are used by experimental chemists to characterize interactions within molecules [56, 57]. As such, we might expect AIM to reveal the presence of CSBs.

\section{Common Trends of Bond Types Revealed by VB, AIM, and ELF}

\subsection{Common Conclusions in VB and AIM Analyses of Bonds}

In order to provide a global picture of the various categories of bonds, we collected 27 bonds in Table 1 [3-15] and organized them into three groups, labeled as (I)(III). The first group involves homonuclear bonds starting from $\mathrm{H}-\mathrm{H}$ all the way to the "inverted" C-C bond in [1.1.1]propellane (see Scheme 3) [11]. Groups (II) and (III) involve heteronuclear bonds, starting from $\mathrm{C}-\mathrm{H}$ all the way to $\mathrm{Si}-\mathrm{F}$.

Each bond in the table is characterized by five VB properties: the weight of the principal VB structure $\left(\omega_{\text {cov }}\right.$ or $\left.\omega_{\text {ion }}\right)$, the bonding energy of that structure $\left(D_{\text {cov }}\right.$ or $\left.D_{\text {ion }}\right)$, the full bond dissociation energy $\left(D_{\mathrm{e}}\right)$, the charge-shift resonance energy $\left(R E_{\mathrm{CS}}\right)$, and the relative resonance energy in percent units $\left(\% R E_{\mathrm{CS}}=100 R E_{\mathrm{CS}} / D_{\mathrm{e}}\right)$. For some of the bonds, we show AIM-derived quantities ( $\rho$ and $\nabla^{2} \rho$ ) as well as the 
Table 1 Bonds and their VB and AIM properties: group (I) corresponds to homonuclear covalent and CS bonds, (II) to heteronuclear covalent and CS bonds, and (III) to ionic bonds

\begin{tabular}{|c|c|c|c|c|c|c|c|c|c|c|}
\hline I. & $\mathbf{A}-\mathbf{A}$ & $\omega_{\mathrm{cov}}$ & $D_{\text {cov }}$ & $D_{\mathrm{e}}$ & $R E_{\mathrm{CS}}$ & $\% R E_{\mathrm{CS}}$ & $\rho$ & $\nabla^{2} \rho$ & $\nabla^{2} \rho_{\mathrm{cov}}$ & $\nabla^{2} \rho_{\text {res }}$ \\
\hline 1 & $\mathrm{H}-\mathrm{H}$ & 0.76 & 95.8 & 105.0 & 9.2 & 8.8 & 0.27 & -1.39 & -0.70 & -0.31 \\
\hline 2 & $\mathrm{Li}-\mathrm{Li}$ & 0.96 & 18.2 & 21.0 & 2.8 & 13.1 & 0.01 & -0.01 & -0.01 & 0.00 \\
\hline 3 & $\mathrm{Na}-\mathrm{Na}$ & 0.96 & 13.0 & 13.0 & 0.0 & 0.2 & 0.01 & 0.00 & 0.00 & 0.00 \\
\hline 4 & $\mathrm{H}_{3} \mathrm{C}-\mathrm{CH}_{3}$ & 0.55 & 63.9 & 91.6 & 27.7 & 30.2 & 0.25 & -0.62 & -0.26 & -0.36 \\
\hline 5 & $\mathrm{H}_{2} \mathrm{~N}-\mathrm{NH}_{2}$ & 0.62 & 22.8 & 66.6 & 43.8 & 65.7 & 0.29 & -0.54 & -0.02 & -0.68 \\
\hline 6 & $\mathrm{HO}-\mathrm{OH}$ & 0.64 & -7.1 & 49.8 & 56.9 & 114.3 & 0.26 & -0.02 & +0.46 & -0.75 \\
\hline 7 & $\mathrm{~F}-\mathrm{F}$ & 0.69 & -28.4 & 33.8 & 62.2 & 183.9 & 0.25 & +0.58 & +1.00 & -0.83 \\
\hline 8 & $\mathrm{Cl}-\mathrm{Cl}$ & 0.64 & -9.4 & 39.3 & 48.7 & 124.1 & 0.14 & +0.01 & +0.14 & -0.26 \\
\hline 9 & $\mathrm{Br}-\mathrm{Br}^{\mathrm{a}}$ & 0.71 & -15.3 & 44.1 & 59.4 & 143.8 & - & - & - & - \\
\hline 10 & $\mathrm{C}-\mathrm{C}_{\text {inv }}(\text { prop })^{\mathrm{b}}$ & 0.62 & -2.2 & $\sim 70$. & 72.2 & $>100$ & $0.19^{c}$ & $+0.43^{c}$ & - & - \\
\hline 11 & $\mathrm{C}-\mathrm{C}_{\mathrm{w}}(\text { prop })^{\mathrm{b}}$ & $\sim 0.55$ & - & - & - & - & $0.25^{\mathrm{c}}$ & $-0.51^{\mathrm{c}}$ & - & - \\
\hline II. & $\mathbf{A}-\mathbf{X}$ & & & & & & & & & \\
\hline 12 & $\mathrm{H}_{3} \mathrm{C}-\mathrm{H}^{\mathrm{a}}$ & 0.69 & 90.2 & 105.7 & 15.1 & 14.3 & - & - & - & - \\
\hline 13 & $\mathrm{H}_{3} \mathrm{Si}-\mathrm{H}^{\mathrm{a}}$ & 0.65 & 82.5 & 93.6 & 11.1 & 11.9 & - & - & - & - \\
\hline 14 & B-H & 0.71 & 78.2 & 89.2 & 11.0 & 12.3 & 0.19 & -0.61 & -0.59 & -0.04 \\
\hline 15 & $\mathrm{Cl}-\mathrm{H}$ & 0.70 & 57.1 & 92.0 & 34.9 & 37.9 & 0.26 & -0.81 & -0.33 & -0.42 \\
\hline 16 & F-H & 0.52 & 33.2 & 124.0 & 90.8 & 73.2 & 0.38 & -2.52 & -1.82 & -0.52 \\
\hline 17 & $\mathrm{H}_{3} \mathrm{C}-\mathrm{F}^{\mathrm{a}}$ & 0.45 & 28.3 & 99.2 & 70.9 & 71.5 & - & - & - & - \\
\hline 18 & $\mathrm{H}_{3} \mathrm{C}-\mathrm{Cl}^{\mathrm{a}}$ & 0.62 & 34.0 & 79.9 & 45.9 & 57.4 & - & - & - & - \\
\hline 19 & $\mathrm{H}_{3} \mathrm{Si}-\mathrm{Cl}^{\mathrm{a}}$ & 0.57 & 37.0 & 102.1 & 65.1 & 63.8 & - & - & - & - \\
\hline 20 & $\mathrm{H}_{3} \mathrm{Ge}-\mathrm{Cl}^{\mathrm{a}}$ & 0.59 & 33.9 & 88.6 & 54.7 & 61.7 & - & - & - & - \\
\hline 21 & $\mathrm{~F}-\mathrm{Cl}^{\mathrm{a}}$ & 0.59 & -39.7 & 47.9 & 87.6 & 182.9 & - & - & - & - \\
\hline 22 & $\mathrm{Cl}-\mathrm{Br}^{\mathrm{a}}$ & 0.69 & -9.2 & 40.0 & 49.2 & 123.0 & - & - & - & - \\
\hline
\end{tabular}


New Landscape of Electron-Pair Bonding: Covalent, Ionic, and Charge-Shift Bonds

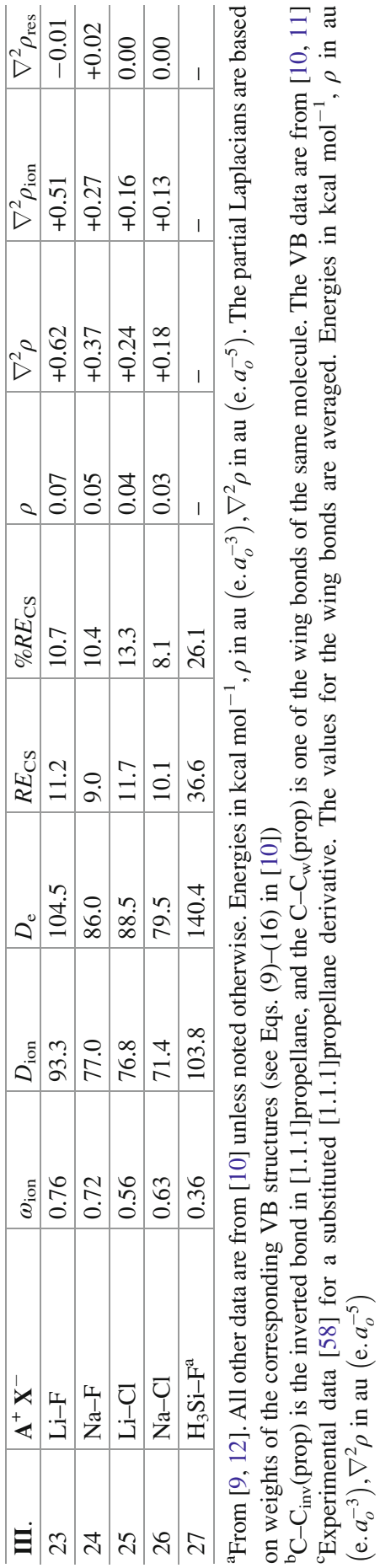


Scheme 3 The molecule [1.1.1]propellane and its two $\mathrm{C}-\mathrm{C}$ bond types

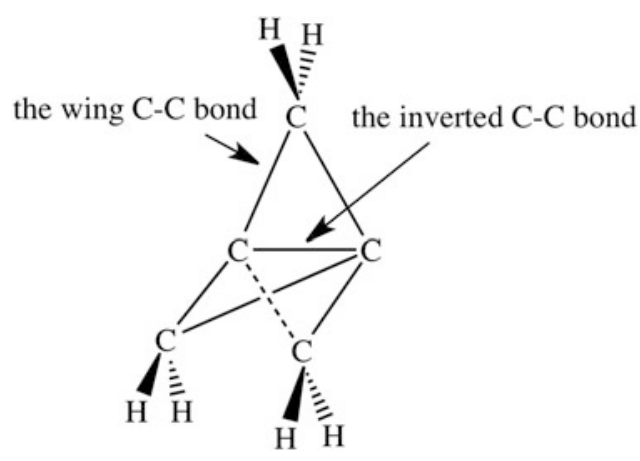

Laplacian components in the BCP for bonding due to the principal structure of the bond $\left(\nabla^{2} \rho_{\text {cov }}\right.$ or $\left.\nabla^{2} \rho_{\text {ion }}\right)$ and the covalent-ionic resonance $\left(\nabla^{2} \rho_{\text {res }}\right)[10]$.

Let us first inspect the homonuclear bonds in (I), which by all definitions could not possess static bond ionicity. The bond energies in entries 1-4 are dominated by the covalent component with charge-shift resonance energy being the minor bonding contribution $\left(\% R E_{\mathrm{CS}}<50 \%\right)$. By contrast, the bonds in entries 6-10 all have a bonding energy dominated by $R E_{\mathrm{CS}}\left(\% R E_{\mathrm{CS}}>100 \%\right)$, while the covalent structure is repulsive $\left(D_{\text {cov }}<0\right)$. The $\mathrm{N}-\mathrm{N}$ bond, entry 5 , is a borderline case, with $\% R E_{\mathrm{CS}}$ accounting for $66.6 \%$ of the total bonding energy. Leaving aside the weak $\mathrm{Na}-\mathrm{Na}$ and $\mathrm{Li}-\mathrm{Li}$ bonds for which all AIM parameters are close to zero, there is an excellent correlation between the $R E_{\mathrm{CS}}$ quantities and the AIM parameters, especially within the same row of the periodic table. Thus, from $\mathrm{C}-\mathrm{C}$ all the way to $\mathrm{F}-\mathrm{F}$ (entries 4-7), the resonance component of the Laplacian $\left(\nabla^{2} \rho_{\text {res }}\right)$ is more and more negative, in line with the increase of $R E_{\mathrm{CS}}$, while the covalent component $\left(\nabla^{2} \rho_{\text {cov }}\right)$ goes from negative to positive values, in line with the repulsive nature of the covalent structure in CS bonds. As a result, the total Laplacian $\nabla^{2} \rho$ is large and negative for classically covalent bonds and small or positive for CS bonds. Note that, according to the computed $R E_{\mathrm{CS}}$ and the experimentally derived $\nabla^{2} \rho$ values [58], the [1.1.1]propellane molecule displays the two categories of bonds, classically covalent for the wing bonds (entry 11) and CS bond for the "inverted" central bond (entry 10). Finally, the coappearance of small or positive total Laplacian $\nabla^{2} \rho$ hand in hand with a significant density, $\rho\left(\mathbf{r}_{\mathrm{c}}\right)$ in homonuclear CS bonds $(\mathrm{HO}-\mathrm{OH}$, $\mathrm{F}-\mathrm{F}, \mathrm{Cl}-\mathrm{Cl}$ ), defines a new bonding category that was not anticipated in the original AIM theory. This is the CSB family.

The above relationships are illustrated more vividly in Fig. 3, which plot the covalent part of the Laplacian against the covalent bond energies, $D_{\text {cov }}$, for homonuclear bonds [10]. In the right lower quadrant, where $D_{\text {cov }}>0$ and $\nabla^{2} \rho_{\text {cov }}<0$, there are the bonds with stabilized covalent bonding. The second group, in the upper left quadrant, involves electronegative and lone-pair-rich atoms and "inverted carbons" which produce CSBs. It can be seen that this bonding type is associated with weakened covalent spin pairing $\left(D_{\text {cov }}<0\right)$, owing to lone-pair repulsion, which raises the kinetic energy as seen from the positive sign of 
Fig. 3 Correlation of the covalent Laplacian (L) with the value of $D_{\text {cov }}$ for homonuclear bonds. The CSBs are concentrated in the upper left quadrant, while the classical covalent bonds are in the lower right quadrant. Note the two bond types of [1.1.1] propellane, each belonging to a different quadrant. Reproduced from [10] with permission of Wiley-VCH

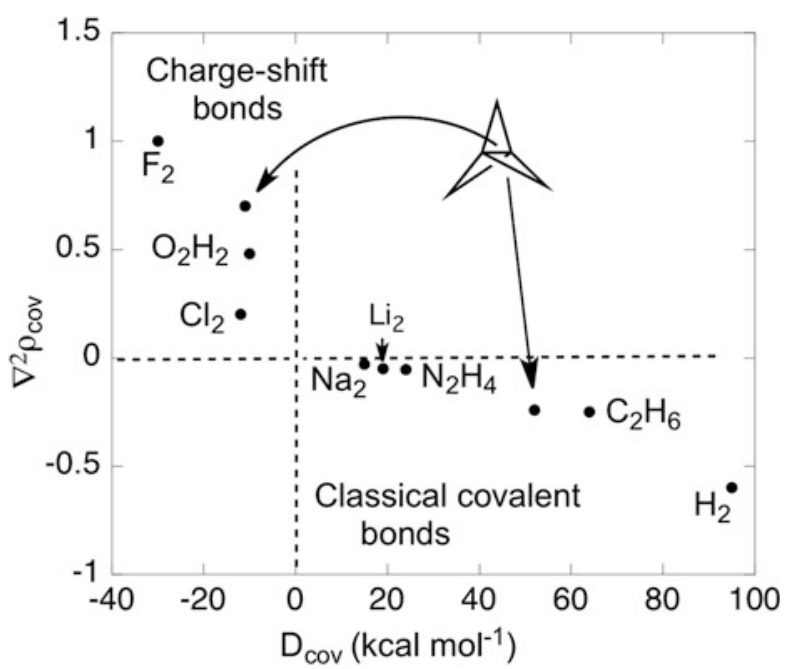

$\nabla^{2} \rho_{\text {cov }}$. Clearly, AIM and VB theory converge, both revealing the presence of a CSB family.

Turning to heteropolar bonds in (II) in Table 1, we note the following trends. While the covalent VB structure is the principal one for all these bonds, still the bonds fall into two distinct groups. Specifically, the bonds in entries 12-15 belong to the classical polar-covalent bond family based on their $\% R E_{\mathrm{CS}}$ that is well below $50 \%$. By contrast, the bonds in entries 16-22 all have weakly bonded covalent structures and large $\% R E_{\mathrm{CS}}$ exceeding $50 \%$ and in some cases $>100 \%$.

In part (III) of the table, the principal VB structure of all bonds is ionic. The bonding energies in entries 23-26 are all dominated by the electrostatic contribution to bonding $\left(D_{\text {ion }}\right)$, with small $R E_{\mathrm{CS}}$ contributions. These are classical ionic bonds. Finally, the Si-F bond in entry 27 is special; its principal VB structure is ionic; its static ionicity is large, but its $R E_{\mathrm{CS}}$ is significant, much larger than that in the classical ionic bonds in (III). VB theory predicts that this bond will be very different from ionic bonds. As already alluded to above, the $\mathrm{Si}-\mathrm{X}$ bonds behave as though they were covalent despite their large ionic characters in terms of charge distribution. Here, in (II) and (III), these bonds and their heavier analogs are clearly marked either as $\mathrm{CS}$ bonds $(\mathrm{Si}-\mathrm{Cl}, \mathrm{Ge}-\mathrm{Cl}$ ) [6] or as bonds with a large $\mathrm{CSB}$ character $(\mathrm{Si}-\mathrm{F})$ [9]. A similar case to $\mathrm{Si}-\mathrm{F}$ was noted recently for protonated methanol [15], wherein the bond wave function is dominated by the VB structure $\mathrm{H}_{3} \mathrm{C}^{+}: \mathrm{OH}_{2}$, but the bond energy is dominated by the $R E_{\mathrm{CS}}$ quantity due to resonance between $\mathrm{H}_{3} \mathrm{C}^{+}: \mathrm{OH}_{2}$ and the corresponding covalent structure, $\mathrm{H}_{3} \mathrm{C} \cdot-\cdot \mathrm{OH}_{2}{ }^{+}$.

The AIM analysis of the heteropolar bonds in (II) does not distinguish between the covalent and CSB cases, but the Laplacian components in the BCP show that the CSBs have more pronounced $\nabla^{2} \rho_{\text {res }}$ values [10], compared with the classical covalent bonds, in line with the dominant $R E_{\mathrm{CS}}$ quantity. Finally, the AIM analysis of the classical ionic bonds in (III) [10] shows the expected characteristics from 
closed-shell interactions; all have positive Laplacians that are dominated by the ionic component, $\nabla^{2} \rho_{\text {ion }}$.

\subsection{Common Conclusions in VB and ELF Analyses of Bonds}

Table 2 collects the ELF results for a group of single bonds, reported in the original literature [9]. For covalent and CSB, we show the population of the disynaptic basin that corresponds to the $\mathrm{A}-\mathrm{X}$ bond, $\bar{N}[V(A, X)]$, and its variance $\sigma^{2}$, which is a measure of the charge density fluctuation of the bonding electrons. For ionic bonds (entries 6,7$)$, the core population of the most electropositive atom $\mathrm{A}$ is reported instead of $\bar{N}[V(A, X)]$.

Table 2 exhibits three groups of bonds. Entries 1-5 show bonds with almost 2.0 electrons in the disynaptic basin, with weak to moderate fluctuation compared to the total population. These are the classical covalent bonds.

Entries 6 and 7 of Table 2 show two bonds, which do not exhibit any disynaptic basin but possess a basin for the bare core of sodium. The other basin, which is not shown, resides on the electronegative atoms $\mathrm{Cl}$ and $\mathrm{F}$. In both entries, the population of the core basin of sodium is close to $10 \mathrm{e}-$, and the variance is rather small $(0.11-0.12)$. These are classical ionic bonds.

Table 2 Populations $\bar{N}(\Omega)$ and population variance $\sigma^{2}$ in ELF basins [9]

\begin{tabular}{|c|c|c|c|c|c|}
\hline Entry & Molecule & Basin & $\bar{N}(\Omega)$ & $\sigma^{2}$ & Bond type \\
\hline 1 & $\mathrm{H}-\mathrm{H}$ & $\mathrm{V}(\mathrm{H}, \mathrm{H})$ & 2.0 & 0.0 & cov. \\
\hline 2 & $\mathrm{Li}-\mathrm{Li}$ & $\mathrm{V}(\mathrm{Li}, \mathrm{Li})$ & 2.0 & 0.17 & cov. \\
\hline 3 & $\mathrm{CH}_{4}$ & $\mathrm{~V}(\mathrm{C}, \mathrm{H})$ & 1.97 & 0.63 & cov. \\
\hline 4 & $\mathrm{SiH}_{4}$ & $\mathrm{~V}(\mathrm{Si}, \mathrm{H})$ & 2.0 & 0.46 & cov. \\
\hline \multirow[t]{2}{*}{5} & $\mathrm{C}_{2} \mathrm{H}_{6}$ & $\mathrm{~V}(\mathrm{C}, \mathrm{H})$ & 2.0 & 0.63 & cov. \\
\hline & & $\mathrm{V}(\mathrm{C}, \mathrm{C})$ & 1.81 & 0.96 & cov. \\
\hline 6 & $\mathrm{NaCl}$ & $\mathrm{C}(\mathrm{Na})$ & 10.02 & 0.11 & ion. \\
\hline 7 & $\mathrm{NaF}$ & $\mathrm{C}(\mathrm{Na})$ & 10.01 & 0.12 & ion. \\
\hline 8 & $\mathrm{~F}_{2}{ }^{\mathrm{a}}$ & $\mathrm{V}(\mathrm{F}, \mathrm{F})$ & 0.44 & 0.42 & CS \\
\hline 9 & $\mathrm{Cl}_{2}{ }^{\mathrm{a}}$ & $\mathrm{V}(\mathrm{Cl}, \mathrm{Cl})$ & 0.73 & 0.59 & $\mathrm{CS}$ \\
\hline 10 & $\mathrm{Br}_{2}$ & $\mathrm{~V}(\mathrm{Br}, \mathrm{Br})$ & 0.81 & 0.68 & $\mathrm{CS}$ \\
\hline 11 & $\mathrm{FCl}$ & $\mathrm{V}(\mathrm{F}, \mathrm{Cl})$ & 0.39 & 0.35 & $\mathrm{CS}$ \\
\hline 12 & $\mathrm{FBr}$ & $\mathrm{V}(\mathrm{F}, \mathrm{Br})$ & 0.28 & 0.26 & $\mathrm{CS}$ \\
\hline 13 & $\mathrm{ClBr}$ & $\mathrm{V}(\mathrm{Cl}, \mathrm{Br})$ & 0.67 & 0.54 & CS \\
\hline 14 & $\mathrm{H}_{2} \mathrm{O}_{2}$ & $\mathrm{~V}(\mathrm{O}, \mathrm{O})$ & 0.49 & 0.41 & CS \\
\hline 15 & $\mathrm{~N}_{2} \mathrm{H}_{4}$ & $\mathrm{~V}(\mathrm{~N}, \mathrm{~N})$ & 1.16 & 0.77 & $\mathrm{CS}$ \\
\hline 16 & $\mathrm{HF}$ & $\mathrm{V}(\mathrm{H}, \mathrm{F})$ & 1.22 & 0.68 & $\mathrm{CS}$ \\
\hline 17 & $\mathrm{CH}_{3} \mathrm{~F}$ & $\mathrm{~V}(\mathrm{C}, \mathrm{F})$ & 0.86 & 0.64 & $\mathrm{CS}$ \\
\hline 19 & $\mathrm{SiH}_{3} \mathrm{~F}$ & $\mathrm{~V}(\mathrm{Si}, \mathrm{F})$ & 0.27 & 0.24 & ion-CS \\
\hline
\end{tabular}

${ }^{\mathrm{a}} \mathrm{V}(\mathrm{F}, \mathrm{F})$ and $\mathrm{V}(\mathrm{Cl}, \mathrm{Cl})$ are the unions of two monosynaptic basins 
The largest group in Table 2 corresponds to entries 8-17. In all of these bonds, the population of the $\mathrm{A}-\mathrm{X}$ basin is of the order of $1 \mathrm{e}^{-}$or less, and the variances of these populations are large, almost of the same order as the population. The small populations of the disynaptic basins indicate that these are not classical covalent bonds, in which two spin-paired electrons are expected to dominate the bonding energy. In fact, at higher levels of calculations, in the cases of $\mathrm{F}-\mathrm{F}$ and $\mathrm{Cl}-\mathrm{Cl}$, the disynaptic basins are split into two monosynaptic ones that are $0.2 \AA$ apart, and the electrons in the bonding region behave as though the bonds were "dissociated" with significant Pauli repulsion between the electrons. This, together with the large variance, signifies that the bonding in these molecules is dominated by fluctuation of the charge density. This last group of bonds corresponds therefore to the same CSB type that emerges from the VB calculations.

The last entry in Table 2 corresponds to the $\mathrm{Si}-\mathrm{F}$ bond. With the $6-31+\mathrm{G}^{*}$ basis set, this bond reveals a disynaptic $\mathrm{Si}-\mathrm{F}$ basin, with a weak population and large variance, mostly due to the delocalization involving the fluorine lone pairs. Thus, ELF and VB agree that although this bond has high static ionicity, it is a borderline case lying in between the groups of ionic bonds and charge-shift bonds.

Clearly, therefore, much like the VB picture, the ELF analysis reveals the same distinction between the covalent and $\mathrm{CS}$ bond groups [9]. Bonds like $\mathrm{H}-\mathrm{H}, \mathrm{C}-\mathrm{C}$, $\mathrm{Li}-\mathrm{Li}$, etc., possess disynaptic basins with a population close to 2.0 electrons and small variances, whereas bonds like $\mathrm{F}-\mathrm{F}, \mathrm{Cl}-\mathrm{Cl}, \mathrm{O}-\mathrm{O}, \mathrm{Br}-\mathrm{Br}, \mathrm{N}-\mathrm{N}$, and the inverted $\mathrm{C}-\mathrm{C}$ bond of [1.1.1]propellane possess small basin populations $(\leq 1.0)$ [59], with variances as large as the population.

The match between the predictions of the two methods is made vivid by inspecting the homonuclear bonds in Fig. 4, which shows a plot of the basin population bonds vis-à-vis the charge-shift resonance energy. The correlation is apparent; the smaller the basin population, the larger the charge-shift resonance energy. Furthermore, the heavy red circles in Fig. 4 show how the rate of variance

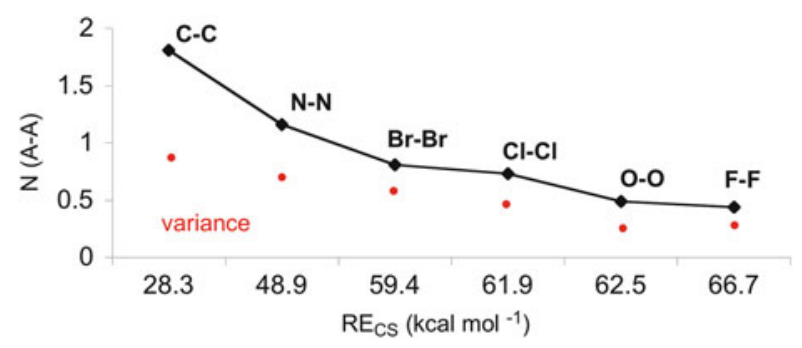

Fig. 4 A correlation between the ELF population of the disynaptic basin and the VB-calculated charge-shift resonance energy, for a series of homonuclear bonds. The heavy red circles show the change of the population variances $\left(\sigma^{2}\right)$ of the bonds. Reproduced from [9] with permission of Wiley-VCH 
over population increases as the $R E_{\mathrm{CS}}$ quantity increases and vice versa. It is apparent that the variance is less than half of the basin population for the covalent bond $(\mathrm{C}-\mathrm{C})$, but it gets gradually closer to the population for the CS bonds (from $\mathrm{Br}-\mathrm{Br}$ to $\mathrm{F}-\mathrm{F})$, thereby showing again the connection between repulsive covalency, the fluctuating electron density, and the large charge-shift resonance energy. Recalling (Table 1) that all the bonds in Fig. 4 have very similar weights of covalent and ionic contributions to bonding, it is clear that the major feature of bonding that distinguishes this group is the $R E_{\mathrm{CS}}$ quantity that arises from the covalent-ionic fluctuation of the pair density.

The correlation in Fig. 4 indicates that both theories converge to the same conclusion, thereby substantiating the classification of CSB as a distinct bonding type that is supported by a dominant $R E_{\mathrm{CS}}$ quantity, due to covalent-ionic fluctuation. Furthermore, both theories show that this group of bonds transcends considerations based on static charge distribution and is more concerned with the "dynamic bond ionicity" (for "dynamic ionicity," see [60]).

\subsection{Common Conclusions in VB, ELF, and AIM Analyses of Bonds}

Figure 5 projects the distinction of the covalent and CSB families by the three theoretical approaches. The figure depicts the ELF molecular basins for $\mathrm{H}_{3} \mathrm{C}-\mathrm{CH}_{3}$, $\mathrm{F}-\mathrm{F}$, and the two $\mathrm{C}-\mathrm{C}$ bond types in [1.1.1]propellane, alongside their VB and AIM properties. It is seen that the $\mathrm{C}-\mathrm{C}$ bond of ethane in Fig. $5 \mathrm{a}$ and the wing $\mathrm{C}-\mathrm{C}$ bond in [1.1.1]propellane in Fig. 5c have nice cylindrical ELF basins with populations close to 2.0, highly negative Laplacians, and a small or moderate $R E_{\mathrm{CS}}$. These are classical covalent bonds. By contrast, Fig. 5b, c shows that the disynaptic basins of $\mathrm{F}-\mathrm{F}$ and the inverted $\mathrm{C}-\mathrm{C}$ bond of [1.1.1]propellane are in fact two monosynaptic basins, much like dissociated bonds. The corresponding basin populations are tiny with variances being as large as the populations, the Laplacian is highly positive indicating repulsive covalent structures, and the $R E_{\mathrm{CS}}$ quantities are very large. Thus, the three methods diagnose the same classification of homonuclear bonds into two families. ELF and AIM diagnose the attractive/repulsive nature of the covalent "shared densities," while VB brings additional energetic insight that highlights the dominant role of the $R E_{\mathrm{CS}}$ energy in the CSB group. Furthermore, the experimentally derived AIM properties for [1.1.1]propellane clearly provide an experimental support for the notion of the CSB character of the inverted $\mathrm{C}-\mathrm{C}$ bond. 
(a)

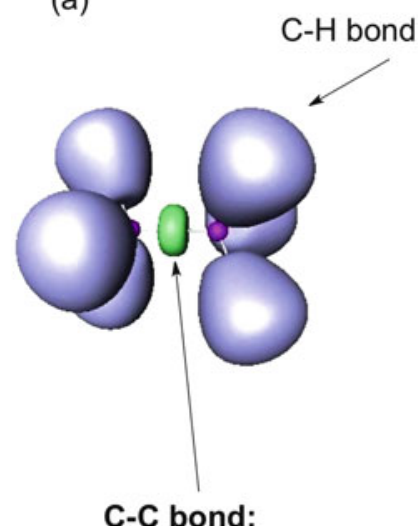

C-C bond: (b)

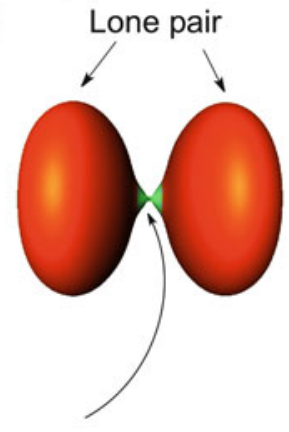

F-F bond:

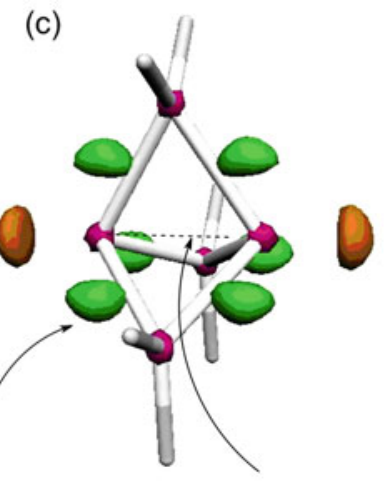

Wing bond: Central bond:

$$
\begin{array}{llll}
R E_{C S}=27.7 & R E_{C S}=62.2 & - & R E_{C S}=72.2 \\
\bar{N}_{\mathrm{CC}}=1.81 & \bar{N}_{\mathrm{FF}}=0.44 & \bar{N}_{\mathrm{CC}}=1.76 & \bar{N}_{\mathrm{CC}}=0.13 \\
\sigma^{2}=0.96 & \sigma^{2}=0.42 & - & \sigma^{2}=0.12 \\
\rho=0.25 & \rho=0.25 & \rho=0.25 & \rho=0.19 \\
\nabla^{2} \rho=-0.62 & \nabla^{2} \rho=+0.58 & \nabla^{2} \rho=-0.51 & \nabla^{2} \rho=+0.43
\end{array}
$$

Fig. 5 Pictorial ELF representations of electron density in a few typical bonds: (a) the ELF disynaptic basin [9] for $\mathrm{H}_{3} \mathrm{C}-\mathrm{CH}_{3}$, (b) the disynaptic and lone-pair basins for the $\mathrm{F}-\mathrm{F}$ bond, and (c) disynaptic basins for the wing bonds of [1.1.1]propellane and two monosynaptic basins for the central inverted bond [59]. Each bond is further characterized by its covalent-ionic resonance energy $R E_{\mathrm{CS}}$, the ELF basin population $\bar{N}$ and its variance $\sigma^{2}$, the density $\rho$ at the bond critical point, and the corresponding Laplacian $\nabla^{2} \rho$ (energies are in $\mathrm{kcal} \mathrm{mol}^{-1}$, densities in $\mathrm{ea}_{0}^{-3}$, Laplacians in $\mathrm{ea}_{0}^{-5}$ ). For $\mathrm{H}_{3} \mathrm{C}-\mathrm{CH}_{3}$ and $\mathrm{F}-\mathrm{F}$, the ELF and AIM parameters are taken from [9] and [11], respectively. For [1.1.1]propellane, the AIM parameters are experimental values [58] from the study of a substituted [1.1.1]propellane derivative. The ELF drawings in this Fig. (a) and (b) are reproduced with permission of Wiley-VCH from Figs. 3 and 4 in [9]. Copyright WileyVCH Verlag \& Co. KGaA. The ELF drawing in this Fig. (c) is reproduced with permission from Fig. 1a in [59]. Copyright Wiley-Interscience

\subsection{The Three Bonding Families}

In summary, CSB emerges as a distinct class alongside the covalent and ionic bonds. In VB theory [3-15], CSB is typified by large covalent-ionic resonance energy, $R E_{\mathrm{CS}}$, and in ELF, by a depleted basin population with large variance and covariance [9]. In addition, homonuclear CSB is characterized in AIM by a positive 
or small Laplacian of the electron density which coappears with a significant value of the density itself, $\rho\left(\mathbf{r}_{\mathrm{c}}\right)[11,54]$. It should be noted that the characterizations of CSB by AIM and ELF electron density analysis are independent of the level of calculation used to compute the wave function or electron density, e.g., MO bonding theory or density functionals [9, 11], showing that the non-VB-based methods effectively account for CSB, even if not in the explicit way achieved by VB theory.

\section{How Does MO Theory Reveal CSB?}

In MO theory, the covalent-ionic resonance energy is embedded into the total energy and is not an immediately apparent property. In addition, the reference state for MO theory is the Hartree-Fock (HF) wave function, which at the same time lacks electron correlation and also does not provide any bonding for F-F. It is therefore challenging to demonstrate that CSB emerges also from MO theory.

Recently, we addressed the challenge and showed that (a) MO-based theory also reveals the CSB family and (b) the bonding in F-F is due to the charge-shift resonance energy. The essential step in this demonstration is the definition of an MO-based reference state that would be identical to the covalent structure of VB theory. While the details appeared recently in the original literature [14], we would like to show here the essential results of the demonstration.

Figure 6 shows the energy curves for the dissociation of $\mathrm{H}-\mathrm{H}$ (Fig. 6a, b) and FF (Fig. 6c, d) using MO-based and VB theories. In the VB curves (Fig. 6b, d), the bond wave function is based on the covalent and ionic structures, while the reference state is the covalent structure as we showed already above. On the other hand, in the MO-based curves (Fig. 6a, c), the bond is described by a two-configuration SCF (TCSCF) wave function and has a reference two-configuration (RTC) state. The construction of RTC state is based on the fact [18] that a bond in the $\mathrm{HF}$ wave function, $\Psi_{\mathrm{HF}}$, involves $50 \%$ covalent and $50 \%$ ionic characters and so does the corresponding doubly excited configuration, $\Psi_{\mathrm{D}}$ (where the two electrons in the $\sigma$-bond orbital are excited to the antibonding $\sigma^{*}$ ). In a homonuclear bond, the only difference is the sign of the combination, $\Psi_{\mathrm{HF}}=\mathrm{cov}+$ ion, while $\Psi_{\mathrm{D}}=\mathrm{cov}-$ ion. Thus, the RTC state is constructed as the wave function obtained by subtracting: $\Psi_{\mathrm{HF}}-\Psi_{\mathrm{D}}$. It is seen from Fig. 6 that the so generated MO-based curves are entirely identical to the corresponding VB curves, one for $\mathrm{H}_{2}$ showing a classical covalent bond, the other for $\mathrm{F}_{2}$ showing CSB.

In fact, it is also possible to define the MO-based curves at higher levels and for other bonds as well. This is illustrated in Fig. 7, which shows the correlation of $\% \mathrm{RE}_{\mathrm{CS}}$ values obtained with TCSCF augmented with second-order perturbation theory (PT2) and those obtained with the BOVB method, for the $\mathrm{C}-\mathrm{C}, \mathrm{N}-\mathrm{N}, \mathrm{O}-\mathrm{O}$, and $\mathrm{F}-\mathrm{F}$ bonds. The correlation is seen to be good and to involve covalent bonds $\left(\% R E_{\mathrm{CS}}<50\right)$ and CSBs $\left(\% R E_{\mathrm{CS}}>>50\right)$. Clearly, CSB is not peculiar to VB theory and it is derivable also from an MO-based theory. It follows therefore that the charge-shift resonance 

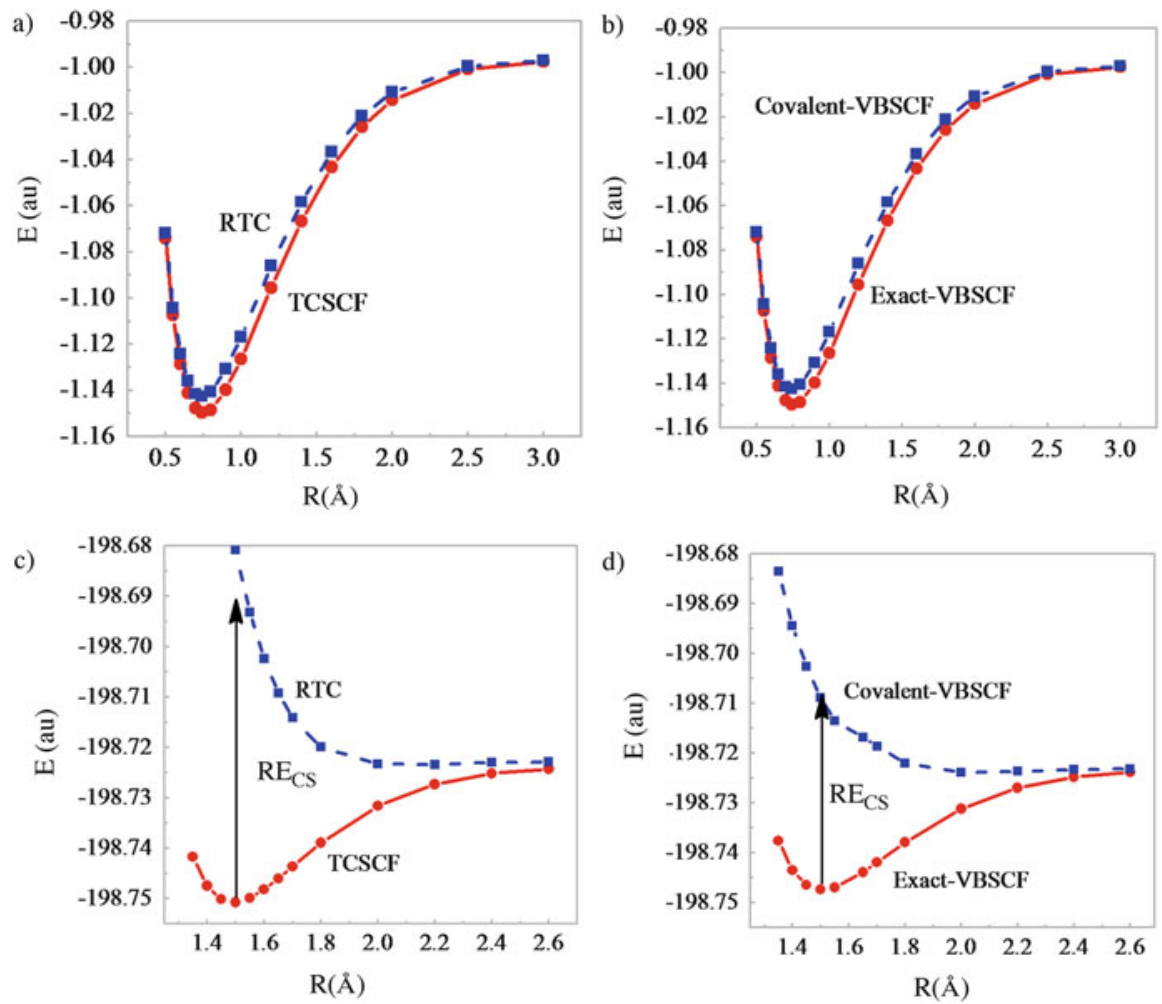

Fig. 6 Full state curves and reference state curves for $\mathrm{H}-\mathrm{H}$ and $\mathrm{F}-\mathrm{F}$ bonds. The MO-generated curves involve two-configuration self-consistent field (TCSCF) wave functions and reference two-configuration (RTC) states, while the VB curves are covalent and full covalent-ionic state curves: (a) and (b) show the dissociation curves for $\mathrm{H}-\mathrm{H}$. (c) and (d) show the corresponding curves for $\mathrm{F}-\mathrm{F}$. The arrow for $\mathrm{F}-\mathrm{F}$ shows the magnitude of the $R E_{\mathrm{CS}}$ as the difference between the reference state (covalent or RTC) and the full state curve. Reproduced with ACS permission from [14]

energy is a fundamental property of the chemical bond that is not specific to any particular computational method or theory.

We can turn now to answer a frequently asked question, "Why do we say that the F-F is bonded by charge-shift resonance, isn't it bonded simply by electron correlation?" The MO-based conclusion that F-F is "bonded by electron correlation" is rooted at the fact that at the HF level the molecule is not bonded and electron correlation, which is brought about by configuration interaction (CI), is required to induce bonding. Let us recall that the $\mathrm{HF}$ wave function $\left(\Psi_{\mathrm{HF}}\right)$ for an electron-pair bond A-A is described by $50 \%$ covalent and $50 \%$ ionic characters, which means that there are identical probabilities for the two electrons to reside on the same atom or being separated apart, one on each atom. Thus, the two electrons in $\Psi_{\mathrm{HF}}$ are not correlated, and electron correlation is obtained by complementing 
Fig. 7 A correlation of $\% R E_{\mathrm{CS}}$ values $\left(\% R E_{\mathrm{CS}}=100 R E_{\mathrm{CS}} / D_{\mathrm{e}}\right)$ obtained at the TCSCF+PT2 level and the BOVB level, for the $\mathrm{C}-\mathrm{C}, \mathrm{O}-\mathrm{O}, \mathrm{N}-\mathrm{N}$, and F-F bonds, from left to right. Reproduced with ACS permission from [14]

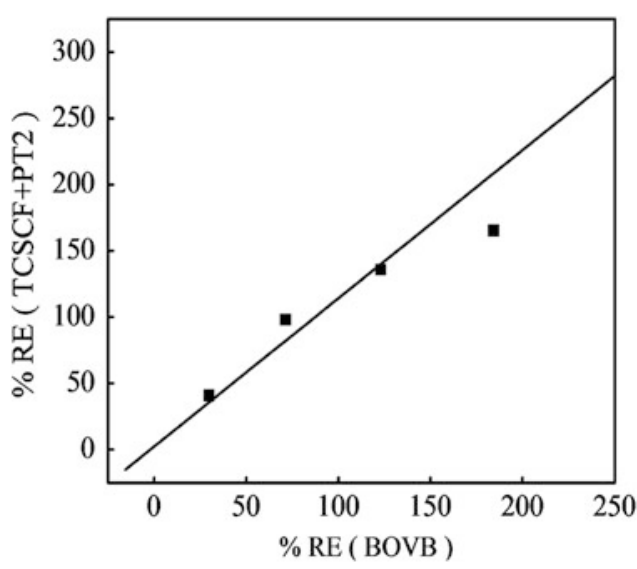

$\Psi_{\mathrm{HF}}$ with CI. The CI raises the weight of the covalent character to ca. $70 \%$ while decreasing the ionic character to ca. $30 \%$, thereby reducing the probability of two electrons to be on the same atom $[18,19]$. By contrast, using the covalent structure as the reference state (either in VB or in MO, as in Fig. 6) causes the electrons to be overly correlated, and the charge-shift resonance energy stabilization brought about by mixing of the ionic structures augments the ionic character while reducing the covalent one. Hence, MO and VB theories start at opposite ends, such that $\mathrm{RE}_{\mathrm{CS}}$ and the correlation energy are completely different physical quantities. However, when we use the same reference state for both VB and MO theories, as in Figs. 6 and 7, we can see clearly the fundamental role of $\mathrm{RE}_{\mathrm{CS}}$ and of CSB. The usage of the artificially high-energy $\Psi_{\mathrm{HF}}$ state, which is fully delocalized (50-50\% ionic/ covalent), masks this fundamental property of the chemical bond.

\section{Physical Origins of CSB}

While the phenomenon of CSB is derived from four independent theoretical treatments, one would still like to base this bonding type on some fundamental principles. All the methods show that the emergence of CSB coincides with poor bonding by the shared-electron density of the electron pair. In VB calculations and MO method using a covalent-reference state, this manifests as a repulsive or weakly attractive covalent structure (Figs. $2 b$ and $6 c, d$ ), in ELF this is shown by escape of the shared density from the disynaptic basin (Figs. 4 and 5), and in AIM one finds that the shared density has a positive Laplacian (Fig. 5) much as in cases which exhibit closed-shell repulsion, e.g., $\mathrm{He}_{2}$. Coupling the AIM technique into VB shows that CS bonds have large resonance Laplacians (entry 7 in Table 1). Furthermore, AIM shows also that the positive Laplacian is associated with excess kinetic energy in the bonding region and the same is implied by the ELF definition. As such, we would like to articulate a physical mechanism that reveals the root causes 
of weakly bonded or repulsive covalent structure and that links this repulsion to increase of kinetic energy of the electrons and the role of $R E_{\mathrm{CS}}$. This is done in the following section.

\subsection{CSB and Atomic Size}

The large $R E_{\mathrm{CS}}$ quantity of CS bonds is an outcome of the mechanism necessary to establish equilibrium and optimum bonding during bond formation. This mechanism, based on the virial theorem, has been analyzed in the original literature in details [4, 9, 61], while here we present a simpler analysis.

By comparing the atomic and covalent radii in the periodic table, one finds that as a rule $r_{\text {atom }}>r_{\text {cov }}$. This means that as atoms (fragments) bind, they shrink [61]. The shrinkage causes a steep increase in the fragments' kinetic energy, which exceeds the lowering of the potential energy due to the diminished size [6268]. Thus, the shrinkage tips the virial ratio of the kinetic $(T)$ vs. potential $(V)$ energies off equilibrium. At equilibrium, the ratio has to be $V / T=-2$. All resonance energy terms are (1) negative and (2) dominated by kinetic energy, and therefore, the covalent-ionic resonance is a negative kinetic energy term that reduces the steep rise in the kinetic energy and restores the virial ratio [4, 9, 6168] and this is true for all bonds. The kinetic energy rise due to shrinkage is proportional to the compactness of bonding partners, and therefore, as the fragments in bonding become more compact, the kinetic energy rise due to the atomic/ fragment shrinkage will get steeper, and a larger $R E_{\mathrm{CS}}$ quantity will be required to restore the equilibrium.

A simple demonstration of the atom compactness effect is Fig. 8 [4], which models the effect of orbital compactness by calculating the CS-resonance energy of

Fig. 8 A natural logarithm plot of the VB-computed [4] CS-resonance energy against the orbital exponent, $\zeta$, for a pseudo- $\mathrm{H}_{2}^{\prime}$ molecule where the $1 \mathrm{~s}$ orbitals of $\mathrm{H}^{\prime}$ have modified orbital exponent, $\zeta$. Adapted with permission from [4]. Copyright 1992

American Chemical Society

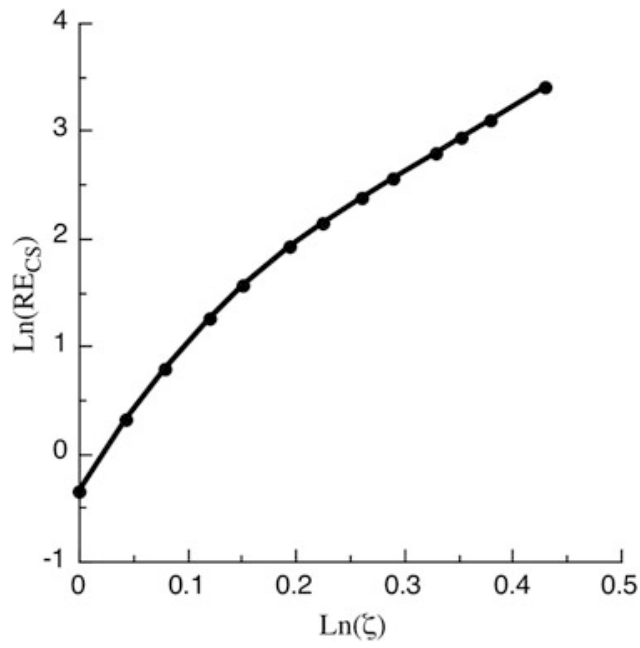


an $\mathrm{H}_{2}^{\prime}$ molecule, where $\mathrm{H}^{\prime}$ is an atom with a variable orbital exponent, $\zeta$. It is seen that as the orbital exponent increases, the CS-resonance energy increases. In the region $\operatorname{Ln}(\zeta)=0.2-0.5$, the relationship is linear following Eq. (9):

$$
\operatorname{Ln}\left(R E_{\mathrm{CS}}\right)=8.9 \operatorname{Ln}(\zeta)-0.4
$$

The result in Fig. 8 and its expression in Eq. (9) are direct demonstrations of the role of the atomic size. Thus, as $\zeta$ increases, the orbital of $\mathrm{H}^{\prime}$ becomes more compact, leading to increase of the kinetic energy of the atoms, and hence, the CS-resonance energy increases in order to restore equilibrium for the bond.

\subsection{The Pauli Repulsion Pressure as a Driving Force for $C S B$}

Real atoms (fragments) are not merely pseudo-hydrogens. They bear also lone pairs or other electron pairs, which can interact with the "test bond" by Pauli repulsion. As we saw, in some bonds like $\mathrm{F}-\mathrm{F}, \mathrm{Cl}-\mathrm{Cl}, \mathrm{O}-\mathrm{O}$, etc., the spin pairing leads to a covalent structure that is either destabilized or only weakly stabilized relative to the dissociated atoms (Table 1). This failure of the covalent structure to provide significant bonding was quantified in VB terms [3-6, 9, 12] and found to originate primarily in the Pauli repulsion between the bonding electrons and the lone pairs that have the same symmetry as the bond. The repulsion between the lone pairs themselves contributes too but to a lesser extent [8]. Scheme 4 illustrates this repulsive interaction that counteracts ${ }^{3}$ the spin-pairing stabilization in F-F $[9,49-$ 51], using a cartoon.

Thus, as argued before [18, 69], and is reiterated in the textbox below, both the spin coupling energy as well as each of the 3-electron repulsion terms have the same expression but with opposite signs. Hence, the two Pauli repulsive terms add up to a larger quantity than the spin-pairing energy, and the covalent structure of F-F is repulsive (Fig. 2b) with a negative $D_{\text {cov }}$ quantity [13]. The same considerations apply to other bonds, which bear lone pairs. In any case, the Pauli repulsion pressure will weaken the corresponding covalent bonding energy.

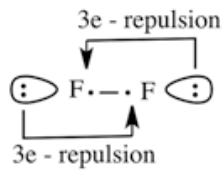

Scheme 4 The lone-pair bond-pair repulsion in the covalent structure of F-F. The bond pair is depicted as two electrons (dots) connected by a line 


\section{Textbox}

Using the Hückel resonance integral $\beta$ and the overlap $S$ between the two hybrid atomic orbitals (HAOs), which participate in spin pairing, the covalent bonding in the F-F bond leads to the following stabilization energy [18, 69]:

$$
\Delta E_{\mathrm{cov}}=2 \beta S ; \quad \beta<0 .
$$

Each of the Pauli repulsion terms in Scheme 4 has the same expression but with a negative sign:

$$
\Delta E_{3 \mathrm{e}-\mathrm{Pauli}}=-2 \beta^{\prime} S^{\prime} .
$$

Therefore, the net $D_{\text {cov }}$ becomes

$$
D_{\text {cov }}=-\left[\Delta E_{\text {cov }}+2 \Delta E_{3 \mathrm{e}-\text { Pauli }}\right]=-2 \beta S+4 \beta^{\prime} S^{\prime}<0 .
$$

Thus, $D_{\text {cov }}$ will be net destabilizing if $\beta S$ and $\beta^{\prime} S^{\prime}$ have comparable magnitudes.

This Pauli repulsion was pointed out originally by Sanderson [31], who termed this as the lone-pair bond-weakening effect (LPBWE). Since the Pauli repulsion has the same expression as the bonding energy but with a different sign [Eq. (11) in the textbox], its presence in a bond will raise the kinetic energy of the bond, and the effect will become more severe as the number of lone pairs on the atom increases. As the atoms (fragments) are brought together, the LPBWE augments the kinetic energy rise since all $-\beta S$ terms are dominated by increase of the kinetic energy. This tips the virial ratio off-balance, and hence the only way for the molecule to restore the virial ratio and achieve equilibrium bonding is to augment the ionic-covalent mixing and increase thereby the CS-resonance energy ${ }^{4}[4,61]$, which reduces the kinetic energy in the bonding region.

\footnotetext{
${ }^{4}$ As seen from footnote 3 here, the F-F bond energy arising from CASSCF or from GVB wave functions is rather poor, $16.0 \mathrm{kcal} \mathrm{mol}^{-1}$. These methods treat the covalent and ionic structures of the bond in a mean-field approximation. Only further extensive CI of the GVB and CASSCF wave functions allows the bond energy to get closer to experiment. The modern BOVB methods lead to the correct bond energy, ca $36 \mathrm{kcal} \mathrm{mol}^{-1}$, by explicit treatment of the ionic structures, which are allowed to take on their particular set of orbitals. Thus bonding in F-F mainly originates from the response of the electronic structure to the fluctuation of the electron-pair density from the average density.
} 
Since electronegative fragments are compact and also lone-pair rich, we might expect that in bonds of such fragments, the resonance energy that is required to restore the virial ratio will become necessarily very large, generating thereby bonds with weakened bonding in the covalent structures and large $R E_{\mathrm{CS}}$ quantities. Thus, CSB is associated with a fundamental mechanism that is necessary to adjust the kinetic and potential energy to the virial ratio at equilibrium, in response to the Pauli repulsive strain exerted on the bond and the shrinkage of the atoms (fragments) that occurs during bonding.

\section{Trends in Electron-Pair Bonds}

Understanding the roots of CS bonding allows us to outline some global correlations for the CS-resonance energy and bonding in general. Recalling that electronegative atoms have compact valence orbitals and are lone-pair rich, we might expect that the electronegativity of the atom or fragment $\left(\chi_{\mathrm{A}}\right)$ will be an organizing quantity for $R E_{\mathrm{CS}}$ and in the absence of LPBWE also of $D_{\mathrm{e}}$.

These global relationships are illustrated in Fig. 9 for $R E_{\mathrm{CS}}$. Figure 9a shows the $R E_{\mathrm{CS}}$ quantities for homonuclear A-A bonds, plotted against the electronegativity $\left(\chi_{\mathrm{A}}\right)$ of $\mathrm{A}$. It is seen that in each period, $R E_{\mathrm{CS}}$ increases as the electronegativity increases. Figure $9 \mathrm{~b}$ shows a plot of $R E_{\mathrm{CS}}$ vs. the sum of electronegativities of the fragments using both homonuclear and heteronuclear bonds [9], while Fig. 9c, d show, respectively, the same trend for $\pi$-bonds of doubly bonded and triply bonded molecules $[7,70]$. It is apparent that the $R E_{\mathrm{CS}}$ quantity of the bond generally increases as the molecular electronegativity of the bond partners increases. We note that the scatter in the plots in Fig. 9b-d reflects in part the effect of the electronegativity difference, namely, the classical Pauling effect on the covalentionic resonance energy [see Eq. (4)]. Thus, for a given molecular electronegativity $\left(\chi_{\mathrm{X}}+\chi_{\mathrm{A}}\right)$, the $R E_{\mathrm{CS}}$ quantity increases, to some extent, with increase of the electronegativity difference $\left(\chi_{\mathrm{X}}-\chi_{\mathrm{A}}\right)$, thereby reflecting an incremental increase of $R E_{\mathrm{CS}}$ due to the stabilization of the ionic structure, $\mathrm{A}^{+} \mathrm{X}^{-}$, and its stronger mixing into the covalent structure. However, the electronegativity difference constitutes only a secondary influence. Indeed, in contrast to the behavior in Fig. 9b-d where a global correlation with $\left(\chi_{\mathrm{X}}+\chi_{\mathrm{A}}\right)$ is apparent, no correlation whatsoever is observed when the $R E_{\mathrm{CS}}$ data is plotted against $\left(\chi_{\mathrm{X}}-\chi_{\mathrm{A}}\right)$ alone. The fundamental correlation is with the sum of electronegativities, which gauges both the effects of the fragment compactness and the Pauli repulsion pressure on the shared density. 

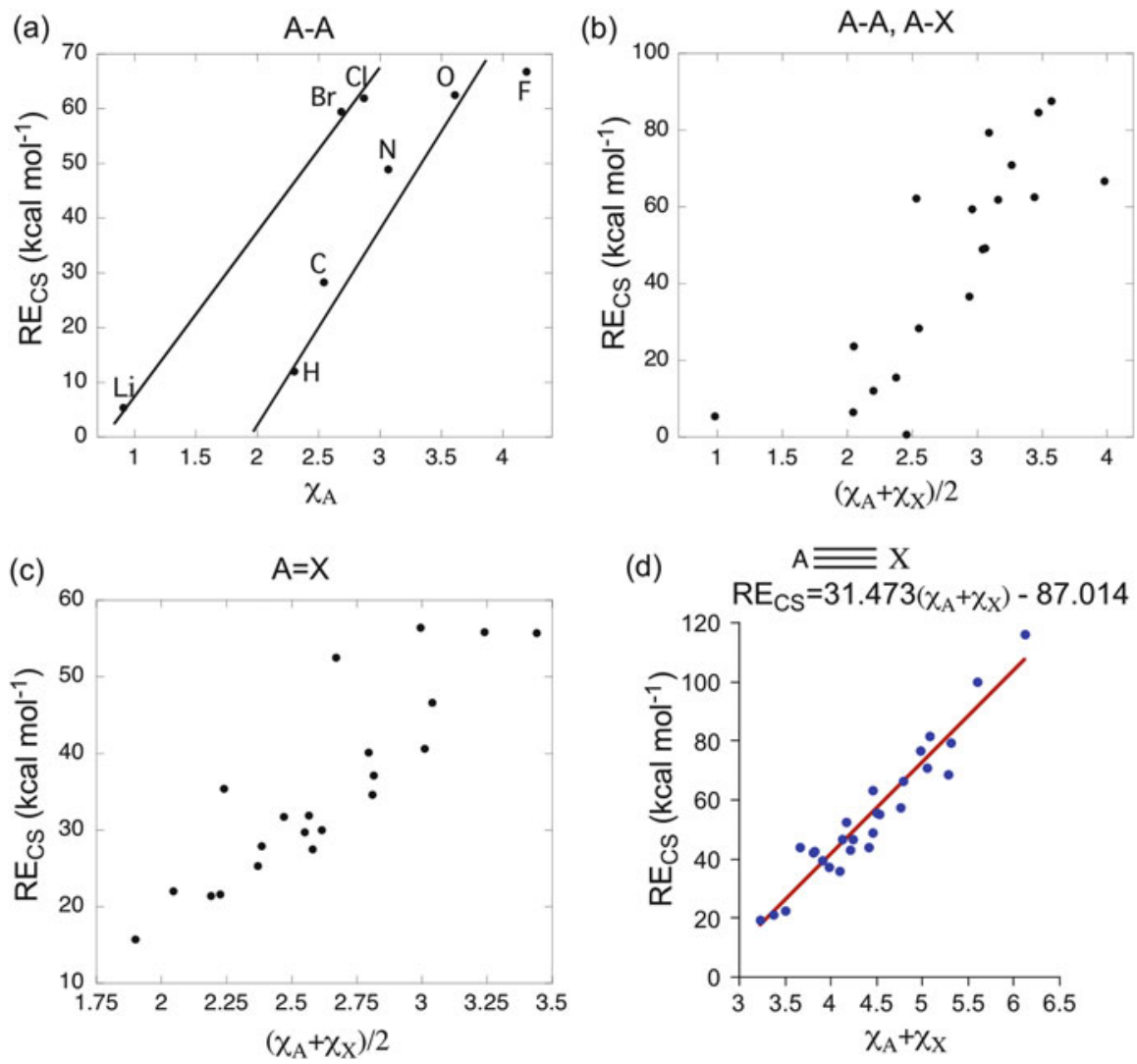

Fig. 9 Correlation of the charge-shift resonance energy $\left(R E_{\mathrm{CS}}\right)$ of a bond with the electronegativities $(\chi)$ of the bonded atoms or fragments. (a) A plot of $R E_{\mathrm{CS}}(\mathrm{A}-\mathrm{A}) \mathrm{vs} \cdot \chi_{\mathrm{A}}$, the electronegativity of $\mathrm{A}$, reproduced from [9] with permission of Wiley- $\mathrm{VCH}$. (b) A plot of $R E_{\mathrm{CS}}$ for $\mathrm{A}-\mathrm{A}$ and $\mathrm{A}-\mathrm{X}$ bonds vs. the average electronegativity of the bond, reproduced from [9] with permission of Wiley-VCH. (c) A plot of $R E_{\mathrm{CS}}$ for $\pi$-bonds (of doubly bonded molecules, $\mathrm{A}=\mathrm{X}$ ) vs. the average electronegativity of the bond partners, reproduced from [9] with permission of Wiley-VCH. (d) A plot of $R E_{\mathrm{CS}}$ for two $\pi$-bonds (of triply bonded $\mathrm{A} \equiv \mathrm{X}$ molecules) vs. the sum of electronegativities of the bond constituents, reproduced with permission from [70]. Copyright 2011 American Chemical Society. Permissions for (a)-(c) are by Copyright Wiley-VCH Verlag \& Co. KGaA. Part (d) is reproduced with permission from [70]. Copyright 2011 American Chemical Society

Since $\pi$-bonds do not suffer from LPBWE, even their $D_{\text {cov }}$ quantity correlates quite well with the sum of electronegativities of the fragments. This along with the dominance of bonding by the $R E_{\mathrm{CS}}$ means that one may expect that the total $\pi$-bond energy will also correlate with the sum of the fragment electronegativities rather than with their difference. Figure 10 shows this global correlation for the total $\pi$-bonding energy in triply bonded molecules, $\mathrm{A} \equiv \mathrm{X}$. Thus, the bonding gets stronger as the molecular electron affinity increases. 
Fig. 10 A plot of VB-calculated sum of $\pi$-bond energies, $D_{2 \pi}$, for $\mathrm{A} \equiv \mathrm{X}$ molecules vs. the molecular electronegativity, $\left(\chi_{\mathrm{A}}+\chi_{\mathrm{X}}\right)$. Reproduced with permission from [70]. Copyright 2011 American Chemical Society

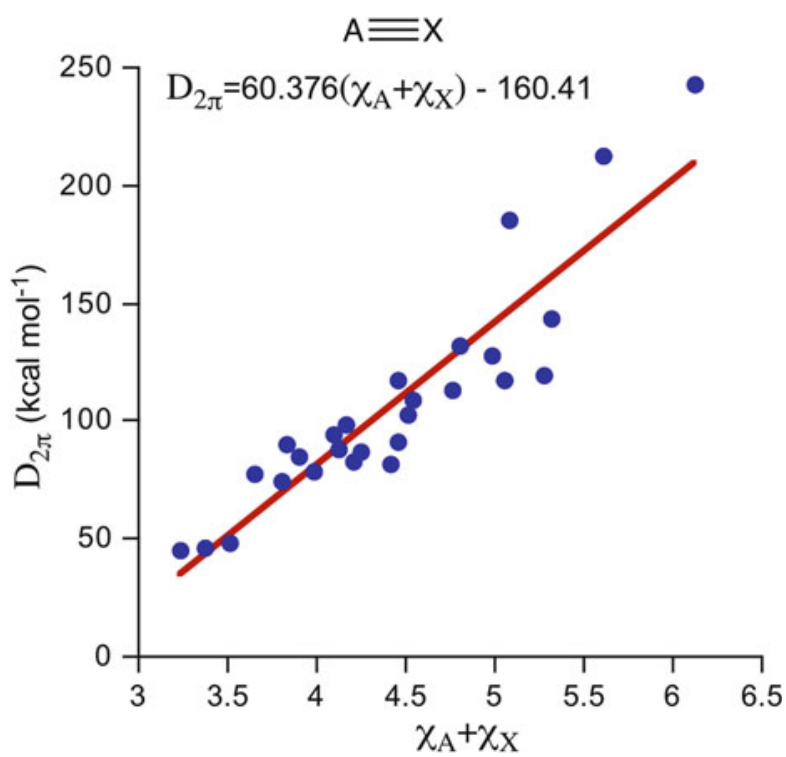

\section{Additional Factors of CSB}

The Pauli repulsion pressure that is associated with the lone pairs of electronegative fragments is not the only factor that can promote CSB. A recently identified additional factor [4-6,9] was expressed in bonds between metalloids of group 14 and electronegative groups, like all the $\mathrm{Si}-\mathrm{F}, \mathrm{Si}-\mathrm{Cl}$, and $\mathrm{Ge}-\mathrm{Cl}$ bonds in Table 1. The VB calculations for these bonds $[6,71]$ show that the corresponding ionic curve for, e.g., the $\mathrm{Me}_{3} \mathrm{Si}-\mathrm{Cl}$ bond is much deeper than that for the corresponding $\mathrm{Me}_{3} \mathrm{C}-$ $\mathrm{Cl}$ bond [71]. Moreover, the ionic curve $\mathrm{Me}_{3} \mathrm{Si}^{+} \mathrm{Cl}^{-}$has a tighter minimum than $\mathrm{Me}_{3} \mathrm{C}^{+} \mathrm{Cl}$ in harmony with the fact that the charge is completely localized on $\mathrm{Si}$ in $\mathrm{Me}_{3} \mathrm{Si}^{+}$, while highly delocalized in $\mathrm{Me}_{3} \mathrm{C}^{+}$. Figure 11 shows the charge distribution in the two cations, and it is apparent that while the $\mathrm{Me}_{3} \mathrm{C}^{+}$carries a tiny little charge on the central carbon, in the case of $\mathrm{Me}_{3} \mathrm{Si}^{+}$all the positive charge is localized on the $\mathrm{Si}$. This causes the ionic and covalent structures to be close in energy in $\mathrm{Me}_{3} \mathrm{SiCl}$, thus leading to a high $R E_{\mathrm{CS}}$ quantity, which is apparent from Table 1 for the $\mathrm{Si}-\mathrm{Cl}$ bond. 

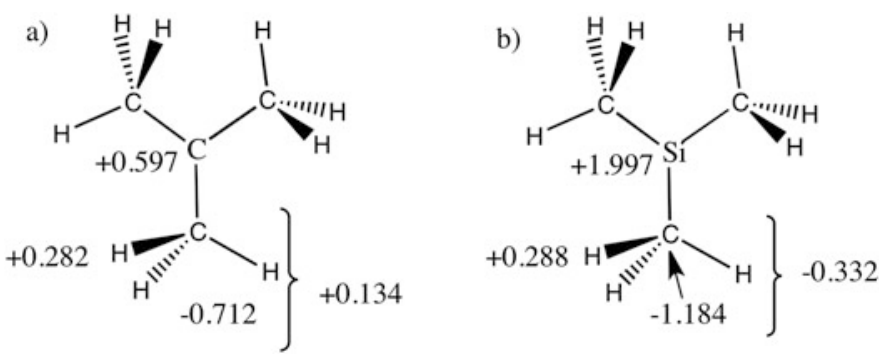

Fig. 11 NBO charge distribution on $\mathrm{Me}_{3} \mathrm{C}^{+}$(a) and (b) $\mathrm{Me}_{3} \mathrm{Si}^{+}$(calculated by $\mathrm{NBO}$ using B3LYP/cc-pVTZ level)

\section{Transforming Covalent Bonds to CSBs by Substitution}

We have discussed above the molecule [1.1.1]propellane and its curious inverted $\mathrm{C}-\mathrm{C}$ bond, which was identified as a CSB, by contrast to the classical covalent wing $\mathrm{C}-\mathrm{C}$ bonds $[11,58]$. This is an interesting finding because it shows that bonds having the same atomic constituents can be either covalent or CSBs, depending on their molecular environment. Understanding the origins of $\mathrm{CS}$ bonding in the inverted $\mathrm{C}-\mathrm{C}$ bond of [1.1.1]propellane is therefore important.

Figure 12 shows that the inverted bond in [1.1.1]propellane is embedded inside a cage of six wing $\mathrm{C}-\mathrm{C}$ bonds, labeled as $\sigma_{\mathrm{w}}$. If we make symmetry-adapted combinations of these six localized bonds, we find that two of the combinations possess the same symmetry as the inverted $\mathrm{C}-\mathrm{C}$ bond and their electron densities are projected on the inverted bond. One of these is a cage orbital $\left(\sigma_{\text {cage }}\right)$, which consists of three lobes pointing from the $\mathrm{CH}_{2}$ moieties of the propellane to the center of the inverted bond, and the second one is the all-positive combination of the wing orbitals that projects on the axis $\left(\sigma_{\text {axis }}\right)$. These two electron pairs repel the covalent structure of the inverted bond, making it repulsive much like in F-F (see above textbox) and eliciting thereby a large $R E_{\mathrm{CS}}$, which makes the inverted bond a CS bond.

Understanding this principle, we can now set out to design a series of $\mathrm{C}-\mathrm{C}$ bonds, which exhibit an excursion from classical covalent bonds to CS bonds [13]. The molecules are depicted in Scheme 5, and the target bond computed with VB theory is shown in a bold line.

For all these bonds, we computed by means of VB theory the bond energy and the $R E_{\mathrm{CS}}$ quantity. For propellanes, one cannot really calculate a bond dissociation energy (BDE), and therefore we calculated for all the molecules the in situ bond

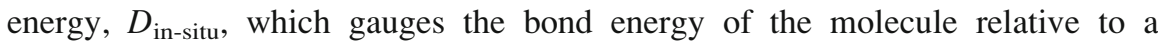
reference nonbonded structure, called the quasi-classical (QC) state [72]. The QC state has a single VB determinant where the spins are not allowed to exchange, and hence its energy does not include any bonding term due to spin pairing. To treat all the bonds in Scheme 5 on equal footing, all the bond energies, even for ethane, were calculated as $D_{\text {in-situ. }}$. Scheme 6 shows the QC state and the various bond quantities that can be calculated by modern VB theory. 


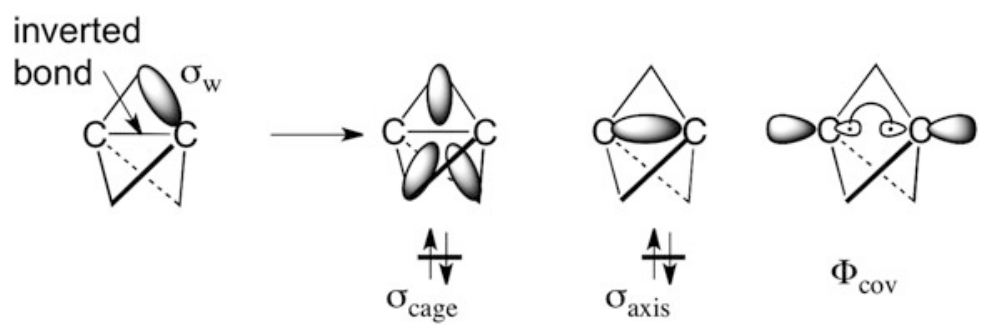

Fig. 12 Covalent bond-weakening repulsion exerted by the wing $\mathrm{C}-\mathrm{C}$ bonds on the inverted central bond of [1.1.1]propellane [13]<smiles>C=[V]C1CCCC1CC1CC1</smiles>

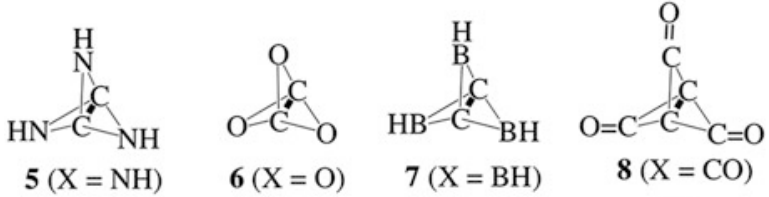

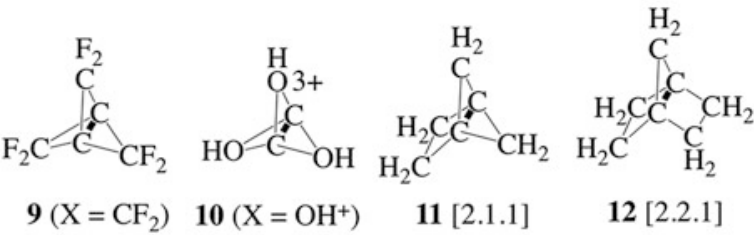<smiles>CC12CCC(C1)C2</smiles>

$13[2.2 .2]$

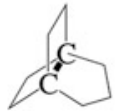

$14[3.2 .2]$

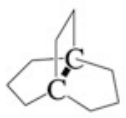

$15[3.3 .2]$

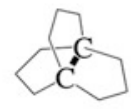

$16[3.3 .3]$

Scheme 5 Target $\mathrm{C}-\mathrm{C}$ bonds highlighted in bold in a series of molecules. The molecules $\mathbf{4 - 1 0}$ are labeled by the wing fragment X. Adapted from [13] with permission of Wiley-VCH

Figure 13 shows a plot of the ratio of $R E_{\mathrm{CS}} / D_{\text {in-situ }}$ vis-à-vis the Laplacian $(L)$ at the bond critical point of the target bonds in Scheme 5. It is seen that the molecules fall into two families. At the lower left quadrant of the plot, we find the $\mathrm{C}-\mathrm{C}$ bonds of ethane, propane, and the large [2.2.2]propellane. All these bonds have a low $R E_{\mathrm{CS}} / D_{\text {in-situ }}$ ratio and negative $L$. Thus, in this family, most of the bond energy arises from the covalent spin pairing, and in accord with that, the Laplacian is negative as expected for classical covalent bonds. By contrast, in the upper right quadrant of Fig. 13, we find the inverted $\mathrm{C}-\mathrm{C}$ bonds of the smaller propellanes and 
New Landscape of Electron-Pair Bonding: Covalent, Ionic, and Charge-Shift Bonds
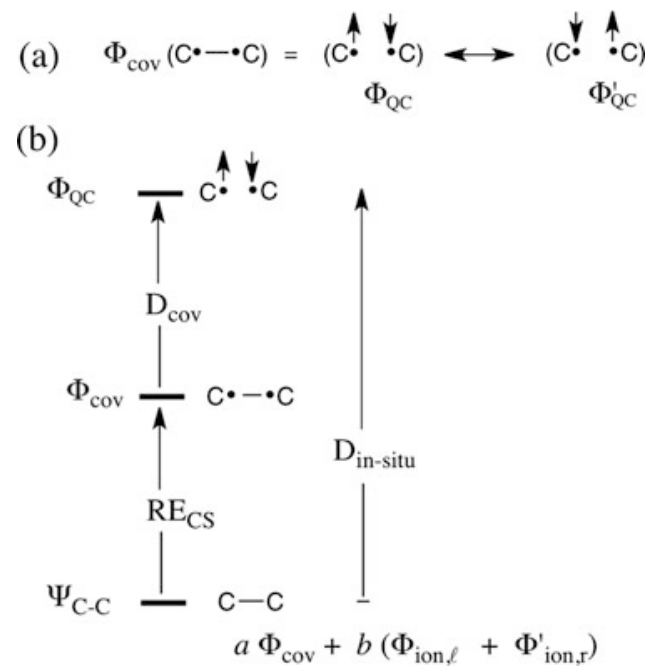

Scheme 6 VB calculations of $D_{\text {in-situ }}$ relative to the QC reference. (a) The constitution of the covalent structure. (b) The $D_{\text {in-situ }}$ value relative to the QC state. Adapted from [13] with permission of Wiley-VCH

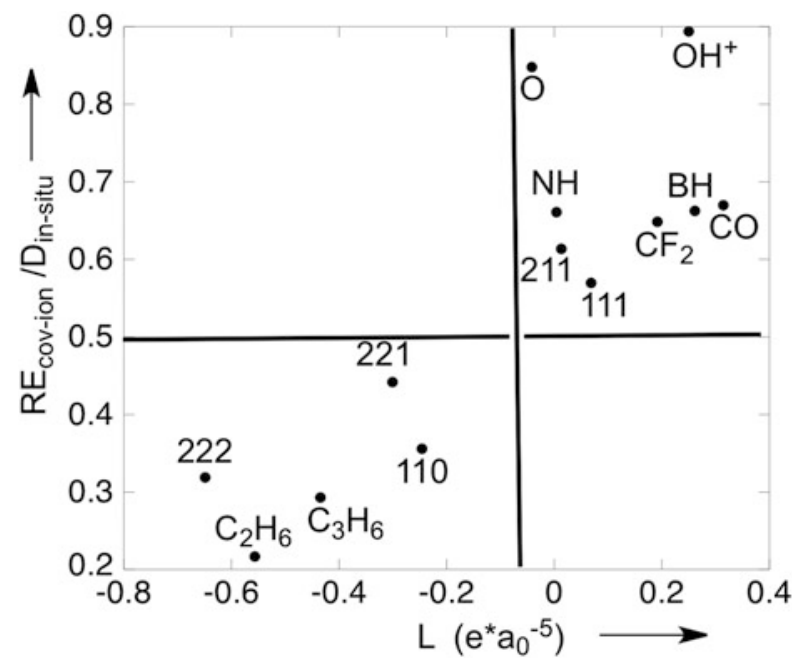

Fig. 13 A two-dimensional plot of $R E_{\text {cov-ion }} / D_{\text {in-situ }}$ (calculated by VB theory) vs. the Laplacian $L$ (calculated by AIM, in atomic units) at the BCP for the target $\mathrm{C}-\mathrm{C}$ bonds in $\mathbf{1}-\mathbf{1 3}$ (Scheme 5), with vertical lines drawn to emphasize the separation into two families of $\mathrm{C}-\mathrm{C}$ bonds. The substituted [1.1.1]- $\mathrm{X}_{3}$-propellanes (4-10 in Scheme 5) are specified by their wing fragment $\mathrm{X}$ ( $\mathrm{X}=\mathrm{CH}_{2}, \mathrm{NH}$, etc.). Reprinted from Fig. 5 in [13] with permission of Wiley-VCH 
the wing substituted ones. All these bonds are typified by a low $R E_{\mathrm{CS}} / D_{\text {in-situ }}$ ratio, which means that most of the bonding arises due to charge-shift resonance, and in accordance, the Laplacian is positive, indicating that these bonds suffer from Pauli repulsion pressure. It is conceivable that such two families of the same homopolar bond may exist for other atoms (fragments).

\section{Experimental Manifestations of CS Bonding}

Having shown the emergence of CS bonding and its promoting factors, here we follow with some evidence for the signature of this bond type in the chemical behavior.

\subsection{Evidence for CSB from Electron Density Measurements}

The existence of the CS bond family will eventually be consolidated by experimental means. One such technique involves the determination of the Laplacian of various bonds from experimental densities, as already done for propellane [58], $\mathrm{N}_{2} \mathrm{O}_{4}$ [73], $(\mathrm{Mg}-\mathrm{Mg})^{2+}$ cores [74], etc. [56, 57]. Thus, as we already alluded to, for [1.1.1]propellane derivatives [58], the experimental Laplacian clearly shows the existence of a classical covalent $\mathrm{C}-\mathrm{C}$ bond in the wing positions vis-à-vis a $\mathrm{CS} \mathrm{C}-\mathrm{C}$ bond in the inverted bond region. Such experimental characterization for other bonds will further show the importance of this new bond family.

In the meantime, the existence of two distinct families has already emerged from electron density difference maps (available experimentally), which plot the difference between the actual molecular density and the density of a reference state made from spherical atoms $\left(\Delta \rho=\rho_{\mathrm{Mol}}-\rho_{\mathrm{Ref}}\right)$, placed at the same geometry as the molecule. These data [75-78] clearly show a group of bonds (e.g., Li-Li, C-C, $\mathrm{Si}-\mathrm{Si}, \mathrm{C}-\mathrm{H}$ ) with $\Delta \rho>0$, which coincides with the classical covalent bond, and a second group (e.g., F-F, Cl-Cl, O-O, S-S, N-N, N-O, C-F, C-O, etc.) of no-density bonds with $\Delta \rho \leq 0$, which coincides with the CS bonding family outlined in this chapter. While the deformation density depends on the definition of the reference atomic state [79] (generally, a better reference state can be made from deformed rather than spherical atoms; see, [80]), the example of [1.1.1] propellanes [75-78] is virtually free of this limitation since the $\Delta \rho$ quantity is determined by comparing two different bonds in the same molecule and using the same $\rho_{\text {Ref. }}$. The findings clearly show that the $\mathrm{C}-\mathrm{C}$ bonds in the wings possess $\Delta \rho>0$, while the "inverted" ( $\mathrm{C}-\mathrm{C}$ ) has $\Delta \rho<0$. Furthermore, these bond types were identified also by the experimental Laplacians, which revealed a fundamental difference between the wing and inverted $\mathrm{C}-\mathrm{C}$ bonds [58]. 


\subsection{Atom Transfer Reactivity as Means of Experimental Quantification of Charge-Shift Resonance Energies}

We would expect to see manifestations of CSB on reactivity for cases that involve cleavage of CS bonds. Our studies [81] showed that one of these manifestations is the computational [82-86] and experimental [87] results that halogen transfer reactions (and especially of fluorine), Eq. (13a), have much larger barriers (by $>20 \mathrm{kcal} / \mathrm{mol}$ for $\mathrm{X}=\mathrm{F}$ ) than the corresponding hydrogen transfer processes, Eq. (13b):

$$
\begin{aligned}
& \mathrm{H} \bullet+\mathrm{X}-\mathrm{H}^{\prime} \rightarrow \mathrm{H}-\mathrm{X}+\bullet \mathrm{H}^{\prime} \\
& \mathrm{X} \bullet+\mathrm{H}-\mathrm{X}^{\prime} \rightarrow \mathrm{X}-\mathrm{H}+\bullet \mathrm{X}^{\prime}
\end{aligned}
$$

Thus, as we demonstrated recently by means of VB calculations [81], the two processes have almost identical barriers for the covalent structures, but they differ in the status of the ionic VB structures near the transition state. In reaction (13a), the key combination of ionic structures, $\mathrm{H} \bullet \mathrm{X}^{-}{ }^{-} \mathrm{H}^{+}$and $\mathrm{H}^{+} \mathrm{X}:{ }^{-} \cdot \mathrm{H}$, is destabilized by two repulsive 3-electron interactions $[18,69,88]$ between $\mathrm{H} \bullet$ and the $\mathrm{X}^{-}$fragment (Scheme 7a). By contrast, the ionic combination $\mathrm{X}:{ }^{-} \mathrm{H}^{+} \cdot \mathrm{X}$ and $\mathrm{X} \cdot \mathrm{H}^{+} \mathrm{X}:{ }^{-}$, for (13b), is devoid of repulsive interactions (Scheme 7b vs. a). The destabilization of the ionic structures during $\mathrm{X}$ transfer results in a loss of $R E_{\mathrm{CS}}$ in the respective transition state. Since the $\mathrm{H}-\mathrm{X}$ bonds, and especially so $\mathrm{H}-\mathrm{F}$, have large $R E_{\mathrm{CS}}$ to begin with, the loss is significant and the barrier is higher for the $\mathrm{X}$ transfer reaction. The largest destabilization occurs for $\mathrm{X}=\mathrm{F}$, since $\mathrm{H}-\mathrm{F}$ has the largest $R E_{\mathrm{CS}}$ quantity among the hydrogen halides.

Interestingly, the barrier difference between the two series was found [81] to follow a very simple relationship, as $1 / 4$ of the $R E_{\mathrm{CS}}$ quantity of the $\mathrm{H}-\mathrm{X}$ bond that undergoes cleavage during the two processes. Therefore, $R E_{\mathrm{CS}}$ is given as:

$$
R E_{\mathrm{CS}(\mathrm{H}-\mathrm{X})} \approx 4\left[\Delta E_{\mathrm{H} / \mathrm{XH}}^{+}-\Delta E_{\mathrm{X} / \mathrm{HX}}^{+}\right]
$$

As such, measurement of the barrier difference for the two series enables to quantify the CS-resonance energy from experimental barriers.

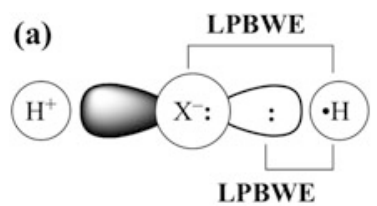

(b)

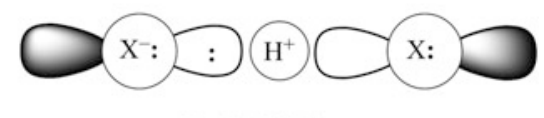

No LPBWE

Scheme 7 Lone-pair bond-weakening effect (LPBWE) in the ionic structure for halogen (X) transfer reactions in (a) and the lack of LPBWE in the ionic structure of $\mathrm{H}$ transfer reactions in (b). Adapted from [9] with permission of Wiley-VCH 


\subsection{Mechanistic Impacts of CSB in the Ionic Chemistry of Silicon in Condensed Phases}

A large CS-resonance energy typifies also bonds with a high static ionicity, like H$\mathrm{F}, \mathrm{C}-\mathrm{F}, \mathrm{Si}-\mathrm{F}, \mathrm{Si}-\mathrm{Cl}, \mathrm{Ge}-\mathrm{Cl}$, etc. (Table 1). This arises due to a combination of effects, one being the atomic shrinkage and LPBWE of the lone-pair-bearing heteroatom and the second being the strong covalent-ionic interaction due to the decreased energy gap between the two structures $[6,12]$. As we mentioned above (Fig. 11), in the case of $\mathrm{Si}-\mathrm{X}$ bonds, the ionic VB structure is highly stabilized because of the concentration of the positive charge on the silicon atom. This leads to some unusual features of the ionic structure as seen in Fig. 14, which compares the location of the energy minima for the ionic and covalent curves for $\mathrm{H}_{3} \mathrm{Si}-\mathrm{Cl}$ vs. $\mathrm{H}_{3} \mathrm{C}-\mathrm{Cl}[5,6]$. Thus, the concentration of the positive charge on $\mathrm{Si}$ shrinks the ionic radius of $\mathrm{H}_{3} \mathrm{Si}^{+}$compared with $\mathrm{H}_{3} \mathrm{C}^{+}$and causes thereby much stronger electrostatic interactions in the ionic structure $\mathrm{H}_{3} \mathrm{Si}^{+} \mathrm{Cl}^{-}$compared with $\mathrm{H}_{3} \mathrm{C}^{+} \mathrm{Cl}^{-}$. The result is that the minimum of the ionic curve becomes very deep for $\mathrm{H}_{3} \mathrm{Si}^{+} \mathrm{Cl}^{-}$ and it coincides with the minimum of the covalent structure, leading thereby to a strong covalent-ionic mixing and large $R E_{\mathrm{CS}}$ compared with the carbon analog (see Table 1). The same situation carries over to any $\mathrm{R}_{3} \mathrm{Si}-\mathrm{Cl}$ vs. $\mathrm{R}_{3} \mathrm{C}-\mathrm{Cl}, \mathrm{R}=$ alkyl, etc. [6]. In a condensed phase, the ionic structure is stabilized by the environment, but since the $\mathrm{Si}^{+} \mathrm{Cl}^{-}$minimum is so tight, the further stabilization by the solvent will be only moderate, and hence, the ionic curve should remain close to the covalent curve, thereby retaining the large $R E_{\mathrm{CS}}$ interaction of the bond. Thus, in a condensed phase, the covalent-ionic mixing remains large giving rise to $\mathrm{Si}-\mathrm{X}$ bonds that stay intact due to the large CS-resonance energy.

Indeed, as discussed above, our recent VB study showed [71] that the $\mathrm{Me}_{3} \mathrm{Si}^{+} \mathrm{Cl}^{-}$ structure in aqueous solution retains the tight ion-pair minimum and thus mixes strongly with the covalent structure and acquires large $R E_{\mathrm{CS}}$. This large $R E_{\mathrm{CS}}$ is the major reason why the bond will not undergo heterolysis in solution (but will prefer associative processes) and why in the solid state even $\mathrm{Ph}_{3} \mathrm{Si}-\mathrm{OClO}_{3}$ is a covalent solid [46] by contrast to the carbon analog, which has an $\mathrm{Na}^{+} \mathrm{Cl}^{-}$type lattice with $\mathrm{Ph}_{3} \mathrm{C}^{+}$and $\mathrm{ClO}_{4}{ }^{-}$ions [42], etc. [40-48].

Fig. 14 Charge distribution and geometric parameters of the ionic structures $\mathrm{H}_{3} \mathrm{C}^{+} \mathrm{Cl}^{-}$and $\mathrm{H}_{3} \mathrm{Si}^{+} \mathrm{Cl}^{-}$, calculated by VB theory. Reproduced from [9] with permission of Wiley-VCH

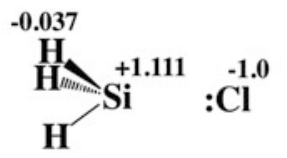

$$
\begin{aligned}
& R_{\min }^{\text {ion }}=2.22 \AA \\
& R\left(\mathrm{SiH}_{3}{ }^{+}\right)=0.31 \AA \\
& R_{\min }^{\text {cov }}=1.97 \AA
\end{aligned}
$$

$$
R_{\min }^{\text {ion }}=2.27 \AA
$$$$
R\left(\mathrm{CH}_{3}{ }^{+}\right)=0.67 \AA
$$

$R_{\min }^{\operatorname{cov}}=1.81 \AA$ 


\section{CSB and Electron-Rich Hypervalent Molecules}

\subsection{Hypervalency of Noble Gas and Isoelectronic Groups}

Xenon and heavier noble gas, as well as sulfur, phosphorus, and chlorine atoms and elements residing below them in the periodic table, have a propensity to seemingly form more bonds than allowed by the traditional Lewis-Langmuir valence rules (e.g., $\mathrm{XeF}_{2}, \mathrm{XeCl}_{2}, \mathrm{KrF}_{2}, \mathrm{RnF}_{2}, \mathrm{ClF}_{3}, \mathrm{SF}_{4}, \mathrm{PCl}_{5}$, and so on), a property referred to as hypervalency. By contrast, lighter elements of the family (e.g., $\mathrm{ArF}_{2}, \mathrm{NF}_{5}, \mathrm{OF}_{4}$, $\mathrm{FF}_{3}$ ) obey the octet rule, showing what has been called the "first-row anomaly." Hypervalency in such electron-rich complexes is generally understood in terms of the 3-center/4-electron (3c/4e) Rundle-Pimentel model [89, 90], which has replaced the old octet-expansion model of Pauling. However, the Rundle-Pimentel model is not always predictive; e.g., it cannot account for "the first-row anomaly" or

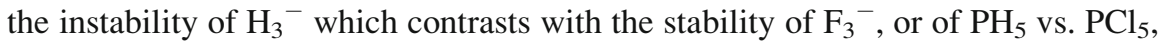
and so on.

Taking $\mathrm{XeF}_{2}$ as a prototype for $3 \mathrm{c} / 4 \mathrm{e}$ systems, Coulson has reexpressed the Rundle-Pimentel model in VB terms by projecting the simple MO wave function on a basis of VB structures [91], thus getting Eq. (15) below:

$$
\begin{aligned}
\Psi\left(\mathrm{XeF}_{2}\right) & =\mathrm{F} \bullet-\bullet \mathrm{Xe}^{+} \mathrm{F}^{-}-\mathrm{F}^{-} \mathrm{Xe}^{+} \bullet-\bullet \mathrm{F}+\mathrm{F}^{-} \mathrm{Xe}^{2+} \mathrm{F}^{-} \\
& +1 / 2\left[\mathrm{~F}^{-} \mathrm{XeF}^{+}+\mathrm{F}^{+} \mathrm{XeF}^{-}+\sqrt{2} \bullet \mathrm{FXeF} \bullet\right]
\end{aligned}
$$

Equation (15) is a good starting point for a VB treatment of hypervalency. Recently, two of us (BB and $\mathrm{PCH})$ used $\mathrm{VB}$ computations and showed that the large atomization energy of $\mathrm{XeF}_{2}$ (ca. $64 \mathrm{kcal} / \mathrm{mol}$ ) cannot arise from the bonding energies of any of the individual VB structures of Eq. (15), which are all largely unbound relative to $\mathrm{Xe}+2 \mathrm{~F} \bullet$. Instead, the stability of $\mathrm{XeF}_{2}$ arises solely from the exceptionally large resonance energy due to the VB mixing of the structures [92], in accord with qualitative predictions that hypervalent compounds should be CSB bound [93].

Actually, the VB calculation [92] showed that a strong CSB character is already present in the normal-valent $\mathrm{F}-\mathrm{Xe}^{+}$species, in which the $\mathrm{RE}_{\mathrm{CS}}$ value, arising from the mixing of the $\mathrm{F}^{+}-\mathrm{Xe}$ and $\mathrm{F}:^{-} \mathrm{Xe}^{2+}$ forms into the purely covalent $\mathrm{F} \bullet-\bullet \mathrm{Xe}^{+}$form, is as large as $69.7 \mathrm{kcal} \mathrm{mol}^{-1}$ ! In the $\mathrm{XeF}_{2}$ complex itself, the stabilization due to the mixing of $\mathrm{F} \bullet-\bullet \mathrm{Xe}^{+}: \mathrm{F}^{-}$and $\mathrm{F}:^{-} \mathrm{Xe}^{+} \bullet-\bullet \mathrm{F}$ is also very large, $82.9 \mathrm{kcal} \mathrm{mol}^{-1}$, and another $70.1 \mathrm{kcal} \mathrm{mol}^{-1}$ is further gained by adding the remaining VB structures of Eq. (15), among which $\mathrm{F}^{-} \mathrm{Xe}^{2+}: \mathrm{F}^{-}$is the most important one. Analogous results were found for other typical hypervalent molecules, $\mathrm{SF}_{4}, \mathrm{PF}_{5}$, and $\mathrm{ClF}_{3}$, isoelectronic to $\mathrm{XeF}_{2}$, in subsequent VB calculations [94]. As in the $\mathrm{XeF}_{2}$ case, the VB structure in which the central atom is doubly ionized was found to be important in all cases. Thus, the model predicts that hypervalency manifests when the central atom (e.g., Xe) has a sufficiently low first ionization potential, as well as a low second ionization potential, and is bonded to electronegative ligands. Adherence or lack of it to these conditions accounts for the stabilities/instabilities of many $3 \mathrm{c} / 4 \mathrm{e}$ systems. 
Table 3 Ionization potentials of the central atom of some hypercoordinated species and their dissociation energies to normal-valent species $+2 \mathrm{~F}$. All energies in $\mathrm{kcal} \mathrm{mol}^{-1}$

\begin{tabular}{l|l|l|l}
\hline Central atom A & 1 st IP of $\mathrm{A}^{\mathrm{a}}$ & 2nd $\mathrm{IP}_{\text {of }} \mathrm{A}^{\mathrm{a}}$ & Dissociation energy $\left(\mathrm{kcal} \mathrm{mol}^{-1}\right)$ \\
\hline $\mathrm{P}$ & 10.5 & 19.7 & $\mathrm{PF}_{5} \rightarrow \mathrm{PF}_{3}+2 \mathrm{~F} \Delta E=187.1^{\mathrm{a}}$ \\
\hline $\mathrm{S}$ & 10.4 & 23.3 & $\mathrm{SF}_{4} \rightarrow \mathrm{SF}_{2}+2 \mathrm{~F} \Delta E=150.7^{\mathrm{b}}$ \\
\hline $\mathrm{Cl}$ & 13.0 & 23.8 & $\mathrm{ClF}_{3} \rightarrow \mathrm{ClF}+2 \mathrm{~F} \Delta E=60.2^{\mathrm{c}}$ \\
\hline $\mathrm{Xe}$ & 12.1 & 21.2 & $\mathrm{XeF}_{2} \rightarrow \mathrm{Xe}+2 \mathrm{~F} \Delta E=64.1^{\mathrm{d}}$ \\
\hline $\mathrm{Kr}$ & 14.0 & 24.4 & $\mathrm{KrF}_{2} \rightarrow \mathrm{Kr}+2 \mathrm{~F} \Delta E=23.1^{\mathrm{e}}$ \\
\hline $\mathrm{Ar}$ & 15.8 & 27.6 & $\mathrm{ArF}_{2}$ unstable \\
\hline $\mathrm{N}$ & 14.5 & 29.6 & $\mathrm{NF}_{5}$ unstable \\
\hline $\mathrm{O}$ & 13.6 & 35.1 & $\mathrm{OF}_{4}$ unstable \\
\hline $\mathrm{F}$ & 17.4 & 35.0 & $\mathrm{~F}_{4}$ unstable \\
\hline $\mathrm{Ne}$ & 21.6 & 41.0 & $\mathrm{NeF}_{2}$ unstable \\
\hline $\mathrm{W}$ & & &
\end{tabular}

${ }^{\mathrm{a}}$ Woon and Dunning [95]

${ }^{\mathrm{b}}$ Woon and Dunning [96]

${ }^{\mathrm{c}}$ Chen et al. [97]

${ }^{\mathrm{d}}$ Pepkin et al. [98]

${ }^{\mathrm{e}}$ Bartlett and Sladky [99]

As an illustration of this point, Table 3 reports the first and second ionization potentials (IPs) for the central atom of some selected neutral hypercoordinated species of the type $\mathrm{AF}_{\mathrm{n}}$, together with the stability of these species with respect to dissociation of the hypervalent bonds. It can be seen that even if the first IP is an important parameter for the stability of $\mathrm{AF}_{\mathrm{n}}$, the second IP is at least as much important and indeed marks the limit between stable and unstable systems and in particular the first-row systems $\left(\mathrm{NF}_{5}, \mathrm{OF}_{4}, \mathrm{~F}_{4}, \mathrm{NeF}_{2}\right)$. The reason for the "first-row exception" is therefore quite clear within the present VB model.

Thus, the general model for hypervalency in electron-rich systems appears to be the VB version of the Rundle-Pimentel model, coupled with the presence of a CSB feature. This latter feature imposes the conditions for manifestation of hypervalency: (1) low first and second ionization potentials for the central atom and (2) ligands that are prone to CSB in their normal-valent states (i.e., being electronegative and bearing lone pairs like F, O, etc.). Lack of any of these features explains the many exceptions to the traditional MO-based Rundle-Pimentel model, like the instability of first-row $3 \mathrm{c} / 4 \mathrm{e}$ systems, as well as that of $\mathrm{ArF}_{2}, \mathrm{H}_{3}{ }^{-}$, and so on.

\subsection{Pentacoordinated Silicon Compounds and Low-Barrier Hydrogen Bonds}

Hypervalency is generally driven by CSB, and hence any species which maintains large covalent-ionic resonance energy, $\mathrm{RE}_{\mathrm{CS}}$, in a hypercoordinated geometry will exhibit hypervalency and give rise to a stable hypervalent species. Silicon is well known for its high propensity to form hypervalent compounds [100-102]; even $\mathrm{SiH}_{5}{ }^{-}$is a stable hypercoordinated species of $\mathrm{D}_{3 \mathrm{~h}}$ symmetry [101, 102]. Similarly, 
even hydrogen exhibits hypervalency in (FHF) ${ }^{-}$, which belongs to the class known as "low-barrier hydrogen bonds" [103]. The root cause of the stability of these hypervalent species is the small size of the cationic state of the central atom, e.g., the silicenium cation, $\mathrm{X}_{3} \mathrm{Si}^{+}$(see Fig. 14), and the proton, $\mathrm{H}^{+}$. Owing to this small size, the triple-ion structure has a tight geometry with short distances, and it lies low in energy; hence, it mixes substantially with the corresponding covalent structures to create a charge-shift bonded hypervalent species. Thus, the triple ionic structure, $\mathrm{F}^{-} \mathrm{H}^{+} \mathrm{F}^{-}$, mixes very strongly with the corresponding covalent structures, $\mathrm{F} \cdot-\cdot \mathrm{H}$ : $\mathrm{F}^{-}$and $\mathrm{F}::^{-} \mathrm{H} \bullet \bullet \cdot \mathrm{F}$, and creates thereby a stable CSB $(\mathrm{FHF})^{-}$species [103]. Similarly, the strong mixing of $\mathrm{X}^{-}\left(\mathrm{X}_{3} \mathrm{Si}^{+}\right)^{-} \mathrm{X}$ with the corresponding covalent structures creates a stable $\mathrm{CSB}\left(\mathrm{SiX}_{5}\right)^{-}$species [103].

\section{Scope and Territory of CS Bonding and Concluding Remarks}

The territory of CSB for electron-pair bonding is in fact larger than we described above. In the area of electron-pair bonds, we should mention the recent VB study [104] by Galbraith who showed that coordinative (dative) bonding such as the one between tetravalent boron and amines, $\mathrm{R}_{3} \mathrm{~B}-\mathrm{NR}_{3}^{\prime}$, is dominated by CS-resonance energy. Similarly, Coote et al. [105] found that the dependence of the relative bond strengths of $\mathrm{R}-\mathrm{X}$ bonds $\left(\mathrm{R}=\mathrm{Me}\right.$, Et, iso- $\mathrm{Pr}$, tert $\left.-\mathrm{Bu} ; \mathrm{X}=\mathrm{H}, \mathrm{F}, \mathrm{OH}, \mathrm{OCH}_{3}\right)$ follows the CS-resonance energy. Very recently, Ess et al. [15] have found that protonation of alcohols in water converts the $\mathrm{C}-\mathrm{O}$ bond into a complete $\mathrm{CSB}$, i.e., without $R E_{C S}$ these bonds would immediately dissociate. A recent study of $\mathrm{M}-\mathrm{H}$ bonds, where $\mathrm{M}$ is a first-row transition metal [106], showed that the CS-resonance energy is quite significant. In the same $\mathrm{M}-\mathrm{H}$ series, $R E_{\mathrm{CS}}$ was found to increase from left to right in the period and to be affected by the presence of the $2 s^{2} 2 p^{6}$ core electron pairs, which behave as lone pairs on the transition metal. Based on the factors that contribute to the propensity of atoms (fragments) to generate CSB, we may expect bonds of first-row transition metals to be CSBs, especially when the bonding partner is an electronegative and/or lone-pair-rich atom. More such CSBs should be looked for among the bonds between the heavier elements of the periodic table.

We did not discuss in this manuscript odd-electron bonds [107]. In odd-electron bonds like in $\mathrm{F}_{2}{ }^{-}$or $\mathrm{He}_{2}{ }^{+}, \mathrm{H}_{2}{ }^{+}$, etc., the entire bonding arises from the charge-shift resonance energy due to the mixing of the odd-electron structures, as depicted in Scheme 8, for an archetypical odd-electron bond. Thus, for example, the 3-electron structures of $\mathrm{F}_{2}{ }^{-}$are by themselves repulsive partly because of the 3-electron repulsion between the two F moieties [108, 109] and in part because of the Pauli

$$
\mathrm{F}:^{-} \cdot \mathrm{F} \longleftrightarrow \mathrm{F} \cdot: \mathrm{F}^{-} \quad \mathrm{D}_{\mathrm{e}}=30 \mathrm{kcal} / \mathrm{mol}
$$

Scheme 8 The resonance of the two 3-electron VB structures that constitute $\mathrm{F}_{2}{ }^{-}$and its bond dissociation energy (a CCSD(T)/aug-cc-pV5Z datum) 
repulsion from the $\sigma$-lone pairs. Nevertheless, $\mathrm{F}_{2}{ }^{-}$is significantly bonded by ca. $30.0 \mathrm{kcal} \mathrm{mol}^{-1}$, which arises due to a large $R E_{\mathrm{CS}}$ quantity that overcomes the repulsive interaction in the individual VB structures.

Future directions for articulating this bonding motif are many. A fruitful direction is hypercoordination (see above) and aggregation. Thus, for example, the small size of $\mathrm{R}_{3} \mathrm{Si}^{+}$and heavier analogs mean that they will tend to form hypercoordinated compounds in solution, in the solid state [100], and even in the gas phase, where some unusual molecules have been reported [101, 110]. Silicon will also exhibit hypercoordination in bridged delocalized electron-pair systems, $(\mathrm{Si}-\mathrm{X}-\mathrm{Si})^{+}$, which participate in catalytic bond exchange reactions [111, 112]. Metal-metal bonds in some bimetallic complexes could well be $\mathrm{CS}$ bonds, as in $\mathrm{M}_{2}$ (formamidinate) complexes $(\mathrm{M}=\mathrm{Nb}, \mathrm{Mo}, \mathrm{Tc}, \mathrm{Ru}, \mathrm{Rh}, \mathrm{Pd})$ where large positive values of $\nabla^{2} \rho\left(\mathbf{r}_{\mathrm{c}}\right)$ have been reported [113]. Other directions involve the generation of [1.1.1] propellane in which the $\mathrm{CH}_{2}$ wings are substituted by heteroatoms that exert exchange repulsion pressure on the inverted $\mathrm{C}-\mathrm{C}$ bond, e.g., HN, etc. [13]. The in-plane $\pi$-type bond in ortho-benzyne is another bond that suffers from exchange repulsion pressure. Protonation or methylation $\left(\right.$ by $\mathrm{Me}^{+}$) of $\mathrm{C}-\mathrm{N}$ bonds may convert them into $\mathrm{CSBs}^{5}$, a fact that may concern DNA bases, and may have mechanistic effects, as in the protonated arginine in the mechanism of nitric oxide synthase [114]. Bonds under immense external pressure [115] are likely to be CSBs, and encapsulated highly positive ions may well be CS bound [116], etc. A growing territory lies ahead for exploration.

In conclusion, CSB originates from the equilibrium condition of the bond, defined by the virial ratio. It is promoted by two main factors:

(a) By Pauli repulsion that weakens the covalency of the bond and induces large covalent-ionic resonance energies $\left(R E_{\mathrm{CS}}\right)$. This excessive exchange repulsion is typical to electronegative and lone-pair-rich atoms or bonds weakened by exchange repulsion pressure, as the bridgehead $\mathrm{C}-\mathrm{C}$ bond in $[1,1,1]$ propellane and other small-ring propellanes.

(b) Fragments that form extremely small cations, which resemble a proton, with all the positive charge located at the central atom, like in silicenium cation, $\mathrm{R}_{3} \mathrm{Si}^{+}$will promote $\mathrm{CS}$ bonding and hypercoordination, especially with electronegative and lone-pair-rich atoms.

With these promoters, CSB forms a distinct group of bonding that transcends consideration of static charge distribution and that possesses unique chemical signatures. Thus, CSB is not merely an academic abstraction. As new examples or experimental manifestations of CSB will start to accumulate and be recognized, the concept of CSB will gradually find more articulations [117] and ultimately be accepted by the chemical community.

Dedication The paper is dedicated to Walter Thiel, a mensch and a fellow scientist, for his 65th birthday.

\footnotetext{
${ }^{5}$ For a discussion of the $\mathrm{N}-\mathrm{CH}_{3}$ bond energy change due to methyl cation attachment to the nitrogen atom, see [93].
} 


\section{References}

1. Shaik S (2007) J Comput Chem 28:51

2. Shaik S, Hiberty PC (2008) A chemist's guide to valence bond theory. Wiley, Hoboken, pp $1-25$

3. Sini G, Maitre P, Hiberty PC, Shaik SS (1991) J Mol Struct (THEOCHEM) 229:163

4. Shaik S, Maitre P, Sini G, Hiberty PC (1992) J Am Chem Soc 114:7861

5. Lauvergnat DL, Hiberty PC, Danovich D, Shaik S (1996) J Phys Chem 100:5715

6. Shurki A, Hiberty PC, Shaik S (1999) J Am Chem Soc 121:822

7. Galbraith JM, Blank E, Shaik S, Hiberty PC (2000) Chem Eur J 6:2425

8. Lauvergnat D, Hiberty PC (1995) J Mol Struct (THEOCHEM) 338:283

9. Shaik S, Danovich D, Silvi B, Lauvergnat D, Hiberty PC (2005) Chem Eur J 11:6358

10. Zhang L, Ying F, Wu W, Hiberty PC, Shaik S (2009) Chem Eur J 15:2979

11. Wu W, Gu J, Song J, Shaik S, Hiberty PC (2009) Angew Chem Int Ed 48:1407

12. Shaik S, Danovich D, Wu W, Hiberty PC (2009) Nat Chem 1:443

13. Shaik S, Chen Z, Wu W, Stanger A, Danovich D, Hiberty PC (2009) ChemPhysChem 10:2658

14. Zhang H, Danovich D, Wu W, Braida B, Hiberty PC, Shaik S (2014) J Chem Theory Comput 10:2410

15. Anderson P, Petit A, Ho J, Mitoraj MP, Coote ML, Danovich D, Shaik S, Braïda B, Ess DH (2014) J Org Chem 79:9998

16. Silvi B, Savin A (1994) Nature 371:683

17. Bader RFW (1990) Atoms in molecules: a quantum theory. Oxford University Press, Oxford

18. Shaik S, Hiberty PC (2008) A chemist's guide to valence bond theory. Wiley, Hoboken, ch. $3,9,10$

19. Wu W, Su P, Shaik S, Hiberty PC (2011) Chem Rev 111:7557

20. Lewis GN (1916) J Am Chem Soc 38:762

21. Langmuir I (1919) J Am Chem Soc 41:868

22. Jensen WB (1984) J Chem Educ 61:191

23. Heitler W, London F (1927) Z Phys 44: 455-472, English Translation Hettema H (2000) Quantum chemistry classic scientific paper. World Scientific, Singapore, pp 140-155

24. London F (1928) Z Phys 46:455

25. Pauling L (1939) The nature of the chemical bond. Cornell University Press, Ithaca (3rd Edition, 1960)

26. Slater JC (1965) J Chem Phys 43:S11

27. van Vleck JH, Sherman A (1935) Rev Mod Phys 7:167

28. Calvin M (1984) J Chem Educ 61:14

29. Saltzman MD (1996) Bull Hist Chem 19:25

30. Gavroglu K, Simoes A (1994) Stud Biol Phys Sci 25:47

31. Sanderson RT (1983) Polar covalence. Academic, New York

32. Edmiston C, Ruedenberg K (1963) Rev Mod Phys 35:457

33. Rutledge RM, Saturno AF (1965) J Chem Phys 43:597

34. Boys SF (1960) Rev Mod Phys 32:296

35. Foster JM, Boys SF (1960) Rev Mod Phys 32:300

36. Weinhold F, Landis CR (2005) Valency and bonding: a natural bond orbital donor-acceptor perspective. Cambridge Univeristy Press, Cambridge

37. Weinhold F, Landis CR (2012) Discovering chemistry with natural bond orbitals. Wiley, Hoboken

38. Bader RFW, Nguyen-Dang TT (1981) Adv Quantum Chem 14:63

39. Henn J, Ilge D, Leusser D, Stalke D, Engles D (2004) J Phys Chem A 108:9442

40. Apeloig Y (1989) In: Apeloig Y, Rappoport Z (eds) The chemistry of organic silicon compounds, vol 1. Wiley, Chichester, ch. 2

41. Laube T (1995) Acc Chem Res 28:399 
42. Prakash GKS, Keyaniyan S, Aniszfeld SKR, Heiliger L, Olah GA, Stevens RC, Choi H-K, Bau R (1987) J Am Chem Soc 109:5123

43. Kato T, Reed A (2004) Angew Chem Int Ed 43:2908

44. Apeloig Y, Stanger A (1987) J Am Chem Soc 109:272

45. Lambert JB, Kania L, Zhang S (1995) Chem Rev 95:1191

46. Gomes de Mesquita AH, MacGillavry CH, Eriks K (1965) Acta Crystallogr 18:437

47. Lambert JB, Zhao Y (1997) Angew Chem Int Ed Engl 36:400

48. Kim K-C, Reed CA, Elliott DW, Mueller LJ, Tham F, Lin L, Lambert JB (2002) Science 297:825

49. Cremer D, Kraka E (1984) Angew Chem Int Ed Engl 23:627

50. Low AA, Hall MB (1990) In: Maksic ZB (ed) Theoretical models of chemical bonding. Springer, New York, pp 544-591, part 2

51. Schwarz WHE, Valtazanos P, Ruedenberg K (1985) Theor Chim Acta 68:471

52. Lusar R, Beltrán A, Andrés J, Noury S, Silvi B (1999) J Comput Chem 20:1517

53. Silvi B (2003) J Phys Chem A 107:3081

54. Rincon L, Almeida R (1998) J Phys Chem A 102:9244

55. Kraka E, Cremer D (1990) In: Maksic ZB (ed) Theoretical models of chemical bonding. Springer, New York, pp 457-543, part 2

56. Coppens $P$ (2005) Angew Chem Int Ed 44:6810

57. Coppens P (1997) X-ray densities and chemical bonding. Oxford University Press, New York

58. Messershmidt M, Scheins S, Grubert L, Patzel M, Szeimies G, Paulmann C, Luger P (2005) Angew Chem Int Ed 44:3925

59. Polo V, Andres J, Silvi B (2007) J Comput Chem 28:857

60. Maynau D, Malrieu J-P (1998) J Chem Phys 88:3163

61. Hiberty PC, Ramozzi R, Song L, Wu W, Shaik S (2006) Faraday Discuss 135:261

62. Kutzelnigg W (1990) In: Maksic ZB (ed) Theoretical models of chemical bonding. Springer, New York, pp 1-44, part 2

63. Ruedenberg K (1962) Rev Mod Phys 34:326

64. Feinberg MJ, Ruedenberg K (1971) J Chem Phys 54:1495

65. Wilson CQ, Goddard WA III (1972) Theor Chim Acta 26:195

66. Rozendaal A, Baerends EJ (1985) Chem Phys 95:57

67. Ruedenberg K, Schmidt M (2007) J Comput Chem 28:391

68. Bickelhaupt FM, Baerends EJ (2000) Rev Comput Chem 15:1

69. Shaik SS (1989) In: Bertran J, Csizmadia GI (eds) New theoretical concepts for understanding organic reactions, vol C267, NATO ASI series. Kluwer, Dordrecht, pp 165-217

70. Ploshnik E, Danovich D, Hiberty PC, Shaik S (2001) J Chem Theory Comput 7:955

71. Su P, Song L, Wu W, Shaik S, Hiberty PC (2008) J Phys Chem A 112:2988

72. Hiberty PC, Danovich D, Shurki A, Shaik S (1995) J Am Chem Soc 117:7760

73. Messerschmidt M, Wagner A, Wong MW, Luger P (2002) J Am Chem Soc 124:732

74. Platts JA, Overgaard J, Jones C, Iversen BB, Stasch A (2011) J Phys Chem A 115:194

75. Dunitz JD, Seiler P (1983) J Am Chem Soc 105:7056

76. Dunitz JD, Schweizer WB, Seiler P (1983) Helv Chim Acta 66:123

77. Coppens P, Yang YW, Blessing RH, Cooper WF, Larsen FK (1977) J Am Chem Soc 99:760

78. Savariault J-M, Lehmann MS (1980) J Am Chem Soc 102:1298

79. Ruedenberg K, Schwarz WHE (1990) J Chem Phys 92:4956

80. Schwarz WHE, Ruedenberg K, Mensching L (1989) J Am Chem Soc 111:6926

81. Hiberty PC, Megret C, Song L, Wu W, Shaik S (2006) J Am Chem Soc 128:2836

82. O'Neal SV, Schaefer HF III, Bender CF (1974) Proc Natl Acad Sci U S A 71:104

83. Dunning TH Jr (1984) J Phys Chem 88:2469

84. Bender CF, Garrison BJ, Schaefer HF III (1975) J Chem Phys 62:1188

85. Voter AF, Goddard WA III (1981) J Chem Phys 75:3638

86. Dobbs KD, Dixon CA (1993) J Phys Chem 97:2085

87. Bartoszek FE, Manos DM, Polanyi JC (1978) J Chem Phys 69:933 
88. Shaik S, Hiberty PC (2004) Rev Comput Chem 20:1

89. Hach RJ, Rundle RE (1951) J Am Chem Soc 73:4321

90. Pimentel GC (1951) J Chem Phys 19:446

91. Coulson CA (1964) J Chem Soc 1442

92. Braida B, Hiberty PC (2013) Nat Chem 5:417

93. Shaik SS (1991) In: Maksic ZB, Maksic ME (eds) An encomium to Linus Pauling.

Molecules in natural science and medicine. Ellis Horwood, London

94. Braida B, Ribeyre T, Hiberty PC (2014) Chem Eur J 20:9643

95. Woon DE, Dunning TH Jr (2010) J Phys Chem A 114:8845

96. Woon DE, Dunning TH Jr (2009) J Phys Chem A 113:7915

97. Chen L, Woon DE, Dunning TH Jr (2009) J Phys Chem A 113:12645

98. Pepkin VI, Lebedev YA, Apin AY (1969) Zh Fiz Khim 43:869

99. Bartlett N, Sladky FO (1973) In: Blair JC, Emeleus HJ (eds) Comprehensive inorganic chemistry, vol 1. Pergamon, Oxford, Chapter 6

100. Kost D, Kalikhman I (2009) Acc Chem Res 42:303

101. Hajdasz DJ, Squires RR (1986) J Am Chem Soc 108:3139

102. Sini G, Ohanessian G, Hiberty PC, Shaik SS (1990) J Am Chem Soc 112:1407

103. Shaik S, Shurki A (1999) Angew Chem Int Ed 38:586

104. Fiorillo AA, Galbraith JM (2004) J Phys Chem A 108:5126

105. Coote ML, Pross A, Radom L (2003) Org Lett 5:4689

106. Galbraith JM, Shurki A, Shaik S (2000) J Phys Chem 104:1262

107. Hiberty PC, Humbel S, Danovich D, Shaik S (1995) J Am Chem Soc 117:9003

108. Hiberty PC, Humbel S, Archirel P (1994) J Phys Chem 98:11697

109. Wu W, Shaik S (1999) Chem Phys Lett 301:37

110. Dávalos JZ, Herrero R, Abboud J-LM, Mó O, Yáñez M (2007) Angew Chem Int Ed 46:381

111. Panisch R, Bolte M, Müller T (2006) J Am Chem Soc 128:9676

112. Lühmann N, Panisch R, Hirao H, Shaik S, Müller T (2011) Organometallics 30:4087

113. Llusar R, Beltran A, Andrés J, Fuster F, Silvi B (2001) J Phys Chem A 105:9460

114. Cho KB, Carvajal MA, Shaik S (2009) J Phys Chem B 113:336

115. Grochala W, Hoffmann R, Feng J, Ashcroft NW (2007) Angew Chem Int Ed 46:3620

116. Dognon J-P, Clavaguéra C, Pyykkö P (2009) J Am Chem Soc 131:238

117. Rupar P, Straoverov VN, Baines KM (2008) Science 322:1360 